\title{
Graphene Membranes: From Reverse Osmosis to Gas Separation
}

\author{
Gustavo Feliciano de Jesus Barcelos ${ }^{1}$, André Santarosa Ferlauto ${ }^{2}$ and Kátia Cecília de \\ Souza Figueiredo ${ }^{1, *}$
}

\author{
${ }^{1}$ Department of Chemical Engineering, Federal University of Minas Gerais, Avenida Presidente Antônio \\ Carlos, 6627, Pampulha, 31270-901, Belo Horizonte, MG, Brazil \\ ${ }^{2}$ Engineering, Modeling and Applied Social Sciences Center, Federal University of ABC, Avenida dos \\ Estados, 5001, Bangu, 09210-580, Santo André, SP, Brazil
}

\begin{abstract}
Graphene membrane is a promising technology to help both carbon dioxide separation from flue gas and water desalination. This work reported the importance of membrane separation processes, the evolution of polymeric membranes before the discovery of graphene and how this material fits into this scenario. In addition, reverse osmosis and gas separations have been discussed as promising methods to reduce the occurrence of freshwater scarcity events and slow global warming. For all these separation techniques, the current state of graphene membranes technology and what advances might be brought by such one atom thick skin layer were presented, as well as the results of theoretical and experimental research. Finally, the challenges that still need to be overcome by this innovative technology as well as the perspectives were shown.
\end{abstract}

Keywords: Graphene membranes, Transfer method, Polymeric support, Gas separation, Desalination.

\section{INTRODUCTION}

Climatic data indicate the warming of the planet and an increase of $1.5^{\circ} \mathrm{C}$ in global average temperatures until 2030 is predicted, which will bring risk to humans and several other species $[1,2]$. In the same time interval, increases in demand for food and energy by $50 \%$ and water by $30 \%$ are expected, thanks to population and economic growth, which may cause local shortages of fresh water that will put societies, economies and businesses at risk in various parts of the world [1, 3]. In addition to the dangers of both phenomena in isolation, anthropological global warming has the potential to intensify shortages when changing the hydrological cycle and reducing the availability and quality of water in some locations [1].

It is possible to say that the main consequences of global warming on human life and the environment will happen through water [4]. This is because, among other consequences, climate change will increase variability and uncertainty regarding the magnitude and duration of precipitation events, making it difficult to manage water resources and to plan, design and operate hydrological systems based on historical statistics [4]. In addition, phenomena such as droughts and heatwaves, for example, when they occur in regions with high water consumption will lead to the depletion of this resource $[1,5]$. Changes in seasons

\footnotetext{
"Address correspondence to this author at the Department of Chemical Engineering, Federal University of Minas Gerais, Avenida Presidente Antônio Carlos, 6627, Pampulha, 31270-901, Belo Horizonte, MG, Brazil

Tel: +55(31)3409-1781; E-mail: katia@deq.ufmg.br
}

will alter food crops and, consequently, demand for water [4]. Finally, the decrease in the flow of some rivers will affect the intake of drinking water, cooling of thermoelectric plants, energy production and navigation [4].

This interaction between climate change and scarcity of fresh water demonstrates the importance of interventions that are simultaneously productive to mitigate both effects, or that at least do not harm one management for the benefit of the other [4]. To exemplify the need for this holistic analysis, the replacement of fossil fuels with biofuels, which will increase its share in road transport from 1 to $4 \%$ by 2030 , despite reducing greenhouse gas emissions, will increase the pressure on water resources and, consequently, on food prices, impacting food security $[4,6]$.

Among the strategies to mitigate the environmental impacts of the chemical industries, the improvement of the separation processes play an important role since they consume 4500 trillion BTU of energy per year only in the United States of America, an amount equivalent to $22 \%$ of energy consumption from factories $[7,8]$. Distillation separation accounts for $49 \%$ of this energy consumption [8]. In many systems, an ecological alternative to the distillation is membrane separation processes, which is energy efficient (as it does not require a thermal driving force), compact, simple to operate, flexible, safe, modular, scalable, combinable with other processes, does not require the use of solvents and is very favorable for small-scale 
operations where the purity required of the products is not critical $[7,8]$.

The membrane is a phase which separates the feed from permeate and controls the permeation of different chemical species upon their physicochemical properties such as size or interaction [9]. Its conventional environmental applications include both the reduction or extinction of waste in production processes, as well as the recovery and recycling of components and the conversion of liquids or gases into environmentally acceptable effluents [7]. Membrane separation is applied, for example, in wastewater treatment from landfill leachate with energy consumption of only $5 \mathrm{kWh} / \mathrm{m}^{3}$ compared to $60 \mathrm{kWh} / \mathrm{m}^{3}$ spent by evaporator separation [7, 10]. In addition, the gas separation membrane market has grown significantly since its inception in the 1970s in applications such as acid gas removal, ammonia purge gas recovery, nitrogen enrichment, refinery gas purification, dehydration, and oxo-chemical synthesis $[8,11]$. In scenarios of scarcity of fresh water, membrane desalination is also an important alternative, already being responsible for the production of 80 million $\mathrm{m}^{3} /$ day of desalinated water serving 200 million people $[8,11,12]$.

Membrane technology cannot meet all the demands of all liquid and gas phase separations and is normally limited by the selectivity or permeability values of the membranes available for a given operation, in addition to factors such as high capital costs, limited capacity for achieve high purity separation or unviability of largescale operation depending on the application $[7,8]$. To extend its applicability, some improvements in the technique are needed [7]. Advances in nanotechnology offer materials such as graphene, which is promising to promote these improvements in membrane structures and properties [11]. This material has unique characteristics, combining attributes such as a single atomic layer structure and a large surface area and the possibility of being joined to another material for the synthesis of smooth, non-toxic, anti-fouling films, with high permeability and selectivity [11].

This work aims to present the state of the art of graphene membranes, as well as the main constraints to its application in large scale membrane processes. The idea of a single atom layer thick membranes can improve the separation of similar molecules such as $\mathrm{CO}_{2} / \mathrm{N}_{2}$ or $\mathrm{NaCl} / \mathrm{H}_{2} \mathrm{O}$, but the technical problems to produce defect-free graphene and the interfacial requirements in the adhesion of such skin to the support. The growing importance of global attention to the development of cleaner technology may surpass the challenges.

\section{GRAPHENE MEMBRANES}

\subsection{Polymeric Membranes}

In the early 1960s, Loeb and Sourirajan developed a cellulose acetate membrane that would become the first reverse osmosis membrane for industrially applicable seawater desalination [13]. The process of synthesis of this membrane consisted of adding magnesium perchlorate to a cellulose acetate solution in acetone followed by immersion in cold water and then heating [13]. The membrane produced by the researchers was fed with brine $(\mathrm{NaCl}$ concentration of $5.25 \%$ ) and had a productivity of 190 to 450 L. m ${ }^{-2}$.day ${ }^{-1}$ of desalinated water $(\mathrm{NaCl}$ concentration of $0.05 \%)$, operating with pressures between 100 and 140 bar [13].

The great feat of these two scientists was to create a semipermeable membrane suitable for the electrolytes present in seawater, capable of demineralizing that water with just one passage and withstanding long periods of operation under high pressures [13]. The enormous impact of this membrane on the desalination market has increased interest in research that has led to the development of other membrane separation processes, such as ultrafiltration, microfiltration, and gas separation [14]. That work, for example, established the synthesis method known as phase inversion that is still used in the production of all commercial gas separation membranes, used in some places in applications such as the processing of 50 to 700 million standard cubic feet of natural gas per day [8].

That study was also important because it evaluated the influence of different treatments, such as heating, on the pore size of the polymers and that size on the flows and on the desalination capacity of the membranes [13]. The work was also notable in establishing that high-flow membranes can be obtained, without compromising selectivity, if the selective layer is as thin as possible, leaving, in the rest of the cross section, large diameter pores that have little resistance to mass transfer [13].

Thanks to the work of Loeb and Sourirajan, in recent decades, researchers have concentrated their efforts in the search for these thin selective layer membranes on a porous polymer that provides mechanical support for this layer $[13,15]$. For the thin 
selective layer, thicknesses of approximately $100 \mathrm{~nm}$ were the thinnest ever achieved in large scale productions without generating pores that would make the use of the membrane unfeasible [15-17]. The porous support has dimensions of about $200 \mu \mathrm{m}$ with up to $10 \%$ porosity, and on the surface the pores should ideally have diameters less than $100 \mathrm{~nm}$ so that the support has a low roughness and adequately accommodates the selective non-porous layer $[15,18$, 19]. The success of this type of membrane on the market is justified because the support can be made from a cheap and mechanically robust engineering thermoplastic and the selective layer, due to its low thickness that requires little raw material, can be made using expensive materials and more efficient, without significantly changing the total cost of the membrane [15].

Although thin film membranes have made great advances in relation to homogeneous membranes, their selective layer is also built from a polymer and polymeric materials in general present a serious problem when applied in separation processes. The socalled trade-off between permeability and selectivity, which compromises the increase of one of these properties to the reduction of the other, an effect that was initially identified in gases, but was later recognized in other separations.

Permeability and selectivity are the main parameters that influence the performance of a membrane applied to gas separation [20]. The permeability to a gas determines the speed of molecular transport across the membrane, being defined by Equation 1:

$P_{i}=\frac{N_{i} L}{\Delta p}$

where $P_{i}$ is the permeability to gas $\mathrm{i}, \mathrm{N}_{\mathrm{i}}$ is the flow of gas $i, L$ is the thickness of the membrane and $\Delta p$ is the pressure difference between the membrane surfaces (or partial pressure difference, for gas mixtures) [15].

Selectivity, in turn, determines the separation efficiency of the desired substance, being defined by Equation 2:

$\alpha_{i, j}=\frac{P_{i}}{P_{j}}$

where $\alpha_{i, j}$ is the selectivity of the membrane for the gas pair $i$ and $j, P_{i}$ being the permeability of the most permeable gas of the pair [15].
Polymeric membranes present considerable problems, including degradation when exposed to certain chemical substances, the inability to satisfactorily separate some mixtures, as well as a very elaborate synthesis process that involves large amounts of volatile and potentially toxic solvents and prevents the application of polymers that are not soluble in them $[15,21]$. However, the trade-off between permeability and selectivity is the biggest of them because all very permeable polymeric membranes are not very selective, while it would be desirable membranes that simultaneously had high permeability and high selectivity [15]. High permeability decreases the membrane area required to treat a fixed amount of mixture, decreasing the investment to purchase membranes [20]. Greater selectivity, in turn, results in a product of greater purity [20].

In an empirical study conducted in 1991, data on permeability and selectivity of homogeneous polymer membranes developed so far for nine gas pairs were compiled $\left(\mathrm{O}_{2} / \mathrm{N}_{2}, \quad \mathrm{CO}_{2} / \mathrm{CH}_{4}, \mathrm{H}_{2} / \mathrm{N}_{2}, \mathrm{He} / \mathrm{N}_{2}, \quad \mathrm{H}_{2} / \mathrm{CH}_{4}\right.$, $\mathrm{He} / \mathrm{CH}_{4}, \mathrm{He} / \mathrm{H}_{2}, \mathrm{H}_{2} / \mathrm{CO}_{2}$ e $\left.\mathrm{He} / \mathrm{CO}_{2}\right)$. In this study, it was observed that, due to the trade-off, the membranes with better performances, normally polymers with high glass transition temperature, rigid structure and with large spacing between chains, were close to a line in a permeability $x$ selectivity graph with the axes on a logarithmic scale $[15,20,22]$. This line was named the upper limit, as illustrated in Figure 1 and described by Equation 3, according to a theoretical model.

$\alpha_{i, j}=\beta_{i, j} P_{i}^{-\lambda_{i, j}}$

The slope $\lambda_{i, j}$ is a factor dependent on the difference between the kinetic diameters of the gas molecules to be separated, whereas the frontal factor $\beta_{i, j}$ depends on the solubility of the gas, on the slope $\lambda_{i, j}$ and on an adjustable constant related to the properties of the polymeric membrane chain $[15,20,22]$.

The upper limits were redefined in a study carried out in 2008, with a much larger data set than the original, considering the membranes that emerged in the 17 years between the first and the second publication [15, 20, 22, 23]. In addition, the new study also analyzed two pairs of gases that were not studied in $1991, \mathrm{~N}_{2} / \mathrm{CH}_{4}$ and $\mathrm{CO}_{2} / \mathrm{N}_{2}$, the latter thanks to the growing importance of $\mathrm{CO}_{2}$ capture in industrial processes [22, 23].

In most cases, as predicted by the theoretical model, only small changes in the positions of the upper 


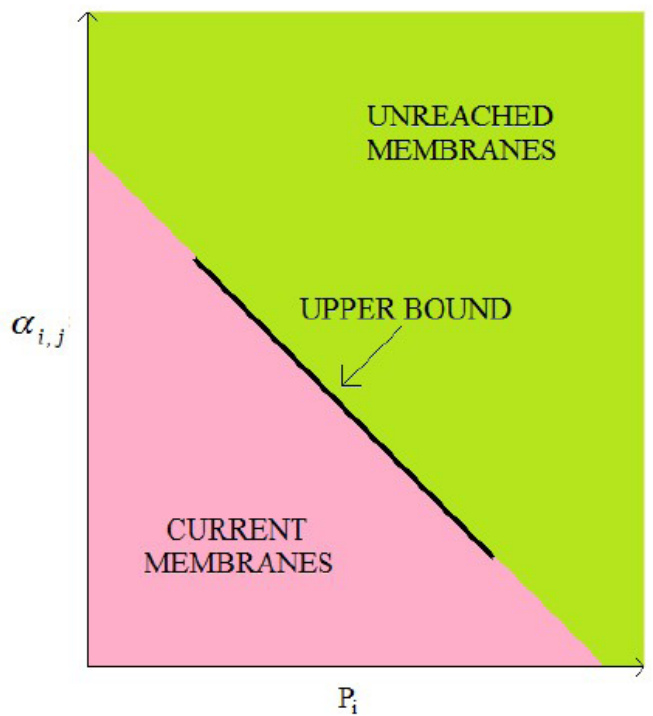

Figure 1: Trade-off between selectivity and permeability in homogeneous polymeric membranes. The ideal materials would be located in the upper right corner of this figure. Axes on a logarithmic scale. Source: Authors.

limits $\left(\beta_{i, j}\right)$ were observed and the slopes $\left(\lambda_{i, j}\right)$ were not changed, since this parameter does not depend on the properties of the polymer [15, 20, 22, 23]. The biggest changes were observed thanks to perfluorinated polymers that significantly improved helium gas separations, for presenting atypical solubility values of this gas [23]. The small changes observed for the other gases were due to polymers with rigid glassy laddertype structures [23].

Although the main studies on this effect on polymeric membranes are carried out in gas separation operations, there are also experimental studies [24] and theoretical model [25] reporting the trade-off between permeability and saline rejection in desalination membranes [15].

The occurrence of this effect in different processes is due to some characteristics of homogeneous polymeric membranes, such as the fact that there are no specific interactions between the substances to be separated and the material of the membrane, which makes it difficult to differentiate between gas molecules or between ions of similar valence, so the distinction occurs only by the size $[15,24]$. In addition, these materials have a wide distribution of size and type of free volume elements, characteristic of polymers, and the impossibility of reducing this amplitude simultaneously with the increase in the average size of these elements $[15,21]$. This means that changes in polymeric structures aiming at increasing the permeability of the species of interest also generate an increase in the permeability of the species that should be retained, causing reductions in selectivity $[15,21]$. Thus, polymers with a high concentration of large cavities and high connectivity between cavities have very high permeability, but their ability to separate small molecules is too low to be useful, in addition to tending to cavity collapse over time due to physical aging [21]. Ideal for making membranes would be polymers with intermediate-sized cavities in the form of necks connecting adjacent chambers (similar in shape to ion channels) and narrow cavity size distribution [21].

The most effective way known today to improve the properties of polymeric membranes is to increase the stiffness of the polymeric matrix (increased selectivity) and, to a certain extent, the spacing between chains (increased permeability), by modifying their chemical structure, but both alternatives have a limited range of results [20]. In addition to these two modifications, the other possibility to achieve, together, high selectivity and permeability values is the use of materials that were not considered in the definition of the upper limit, such as graphene membranes, which have uniform and well-defined porous structures [20,23].

\subsection{Composite Graphene Membranes}

Graphene is a stable and chemically inert material that consists of a sheet of carbon atoms with $\mathrm{sp}^{2}$ hybridization, joined in a hexagonal structure [26]. Its stability combined with its impermeability to any gas [27] and its practically two-dimensional structure (the thinnest material ever discovered, with atomic thickness $-0.37 \mathrm{~nm}$ ) make it one of the existing materials with the greatest potential for making highpermeability membranes $[14,28,29]$. If it becomes a raw material for the manufacture of these membranes, its synthesis process that is likely to achieve greater success is that which produces graphene sheets by CVD (Chemical Vapor Deposition), a technique that uses methane as a carbon source and hydrogen as a carrier gas, temperatures close to $1000{ }^{\circ} \mathrm{C}$ and catalysis by copper substrate with micrometric thickness [28, 30-32]. During synthesis, hydrogen and methane are injected in a preheated and under vacuum reactor, the methane then reacts and deposits carbon atoms on the copper surface [32]. This technique, despite predictably generating graphene of lower quality and still requiring unacceptably long growth times (5-48 h), makes it possible to obtain it in areas of the order of centimeters, in contrast to the small structures obtained from the exfoliation of graphite (< $\left.1000 \mu \mathrm{m}^{2}\right)[28,30,33,34]$. 
The cost-benefit ratio of graphene membranes still needs to be carefully investigated, as significant additional capital expenditure on the membranes is expected due to the complex synthesis of this nanoparticle [28, 33, 35]. Complementary technical studies are also necessary to increase the area of graphene sheets, the elimination of intrinsic crystalline defects that would make it impossible to use graphene as a membrane and the wrinkles associated with the difference in the thermal expansion coefficient between $\mathrm{Cu}$ graphene, as well as the simplification of synthesis procedures $[28,33,35]$. Although graphene sheets with areas on the order of $\mathrm{cm}^{2}$ are sufficient to generate membranes on which characterization tests can be carried out, the usual applications of membranes in industries may require areas of up to $100000 \mathrm{~m}^{2}$ of membranes with defect density less than $1 \mathrm{~cm}^{2}$ of defect for every $10^{5} \mathrm{~cm}^{2}$ of membrane [15-17]. Achieving an area increase of up to eight orders of magnitude without increasing the density of defects is a challenge that graphene membranes will need to overcome in order to become competitive in the market [15].

Once these problems have been solved, the two main challenges are to achieve sufficient mechanical strength to enable handling and to obtain extremely narrow pore size distribution, given that selectivity is highly sensitive to this factor $[28,33,35]$. The stress in a selective membrane increases as a function of $\mathrm{I}^{-3 / 2}$ (where $\mathrm{I}$ is the thickness of the membrane), so an isolated graphene layer, three orders of magnitude thinner than commercial membranes, would suffer a very great stress [14, 36]. This problem can be solved using a strategy similar to that of thin film membranes,
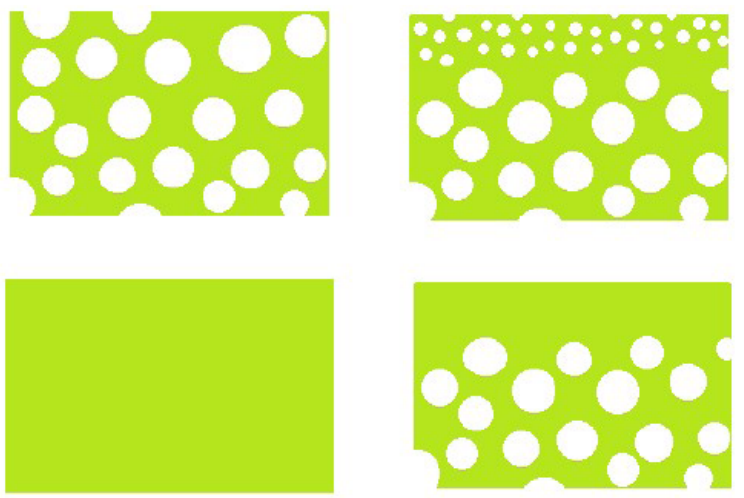

HOMOGENEOUS MEMBRANES

that is, the use of a porous polymeric support layer to support the graphene layer [28, 29]. The support layer would also increase the mechanical resistance inherent to graphene, being indicated by computer simulations that this material supported at every $16 \mathrm{~nm}$ can withstand pressures above 5000 bar without tearing, which would even allow to expand the range of operating conditions currently adopted [37]. Figure 2 illustrates the evolution of the constitution of the membranes, from homogeneous polymeric membranes to graphene membranes, showing in common the fact that all of them need at least one polymer in their composition.

The support is inserted through the transfer process $[30,38]$. The two main transfer methods used in the synthesis of graphene membranes are direct transfer and phase inversion $[30,38]$. Direct transfer consists in the adhesion of the porous polymeric substrate to the free face of graphene by means of a simple pressing process and later copper etching $[30,38]$. When not done correctly, this transfer process introduces tears, cracks, and wrinkles in graphene [30, 38]. Usually, etching is carried out by immersion in ammonium persulfate solution, with the possibility of using iron (III) chloride, however, in this case, copper (I) chloride can be produced and crystallize due to its low solubility, causing rupture of graphene [30]. Due to the large defects generated during etching, sealing is usually necessary to prepare an efficient membrane, a process that is normally carried out by nylon-6.6 interfacial polymerization $[30,38]$.

The five main factors that influence the quality of the direct transfer are the hydrophobicity, roughness and

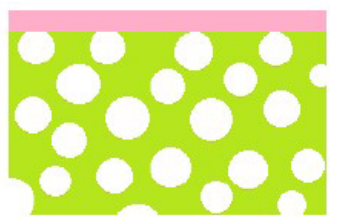

THIN-FILM COMPOSITE MEMBRANES

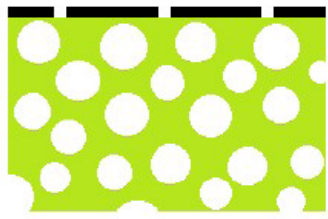

GRAPHENE MEMBRANES
POLYMER A

POLYMER B

GRAPHENE

Figure 2: Illustration of the cross section of different types of membranes used in separation processes. From left to right, the complexity and efficiency of the membranes increase, as well as the thickness of the selective layer reduce. Source: Authors 
porosity of the polymeric support, the roughness of graphene and the type of etchant used to remove copper [30, 38, 39]. The hydrophobicity of the substrate needs to be high enough to prevent the etchant from penetrating the interface between graphene and polymer during copper removal, which could cause the materials to separate $[30,38,39]$. The roughness of the polymeric material, as well as that of graphene, has a negative influence on the quality of contact between graphene and the polymeric material, and therefore ideally both materials should have smooth surfaces, however, mechanisms should be created to ensure that reduction of roughness will not naturally cause a decrease in hydrophobicity $[30,38,39]$. The pore diameters of the support must be small in order to prevent the rupture of unsupported pieces of graphene, thus, as already reported, pores with diameters close to $16 \mathrm{~nm}$ would be reasonable and cannot be too small to the point of making transport of water difficult (diameter $0.3 \mathrm{~nm}$ ) [37]. Finally, the type of etchant must be chosen so that the reaction generates only soluble products, since the appearance of crystals or bubbles on the surface of the polymer or graphene has the potential to separate them $[30,38,39]$.

In phase inversion transfer, a liquid solution of the polymer that will be used as a support is poured and spread over the free face of the graphene [40]. Subsequently, they are immersed in a non-solvent bath that has the function of removing the solvent from the polymeric solution, resulting in the solidification of the polymer at the interface with graphene [40]. This method is also completed by copper etching [40]. Its advantage is that the polymeric solution, being in a liquid phase, can follow the morphology of graphene, increasing its surface area and making the roughness profiles of the surfaces similar after solidification [40]. The best adhesion between graphene and the substrate minimizes empty spaces between materials, tears, cracks, and wrinkles on graphene [40].

After obtaining a fully impermeable surface of supported graphene and, if necessary sealed, it can be transformed into a membrane by introducing artificial nanoscale pores in the graphene structure, for example, using oxygen plasma, helium, or gallium ions $[28,30,41]$. After this process, passivation by functional groups of carbon atoms around the pores is still carried out, in order to avoid atoms with deficiency of chemical bonds, and this step has an important role in determining the transport properties in very small pores [28, 30, 41]. For example, groups that interact intensely with water can hinder the flow of these molecules, while heavily charged groups can delay the transport of solutes due to electrostatic repulsion [28, $30,41]$. Figure 3 illustrates the transfer, etching, sealing and pore creation steps of the graphene membrane synthesis process.

Given the special and innovative characteristics of graphene and the need for a polymeric support, it is necessary to have a thorough knowledge of the properties of polymers in order to optimize them and prevent their limitations from restricting the potential of graphene membranes. Although there are no such indepth studies of the design rules for choosing the substrate of graphene membranes [36] as they exist, for example, for the substrate of thin film membranes [42], some attributes of these supports will be presented below.

The polymer needs to be light, impact resistant, thermally, and chemically stable. It is important that it has an amorphous character, which prevents the formation of the support from being hampered by a crystallization process. It is also interesting that there are already reports of the use of this polymer in processes of separation by membranes and of its synthesis by phase inversion and that it is conformable in the form of hollow fibers, already thinking about a future stage of graphene membranes. Finally, it is important that the polymer has a significant interaction with graphene in order to prevent the occurrence of mechanical failures during the transfer. This can be achieved both by the presence of aromatic rings in the structure, which generate $\pi-\pi$ interactions with graphene [43], and by a high molar mass, which facilitates contact and adsorption by graphene [43].

An example of a polymer that meets these requirements is polymethylmethacrylate (PMMA) [44]. PMMA is lightweight, impact resistant, amorphous [4548] and presents a glass transition at $116^{\circ} \mathrm{C}$ and a single degradation stage at $400{ }^{\circ} \mathrm{C}$ in the thermogravimetric analysis, being therefore thermally stable [49]. The polymer also has reasonable chemical stability (it is not attacked by hydrochloric acid, lactic acid, $10 \%$ sulfuric acid or sodium hydroxide after 30 days of exposure to $50{ }^{\circ} \mathrm{C}$ ) [45-48]. Polymethylmethacrylate has already been formed as hollow fiber and has also been applied, for example, in the $\mathrm{O}_{2} / \mathrm{N}_{2}$ separation, showing good selectivity, despite low permeability, a problem normally minimized using asymmetric configurations obtained by phase inversion [47]. PMMA was already present even at the upper limits of many gas separations in the first study on the 


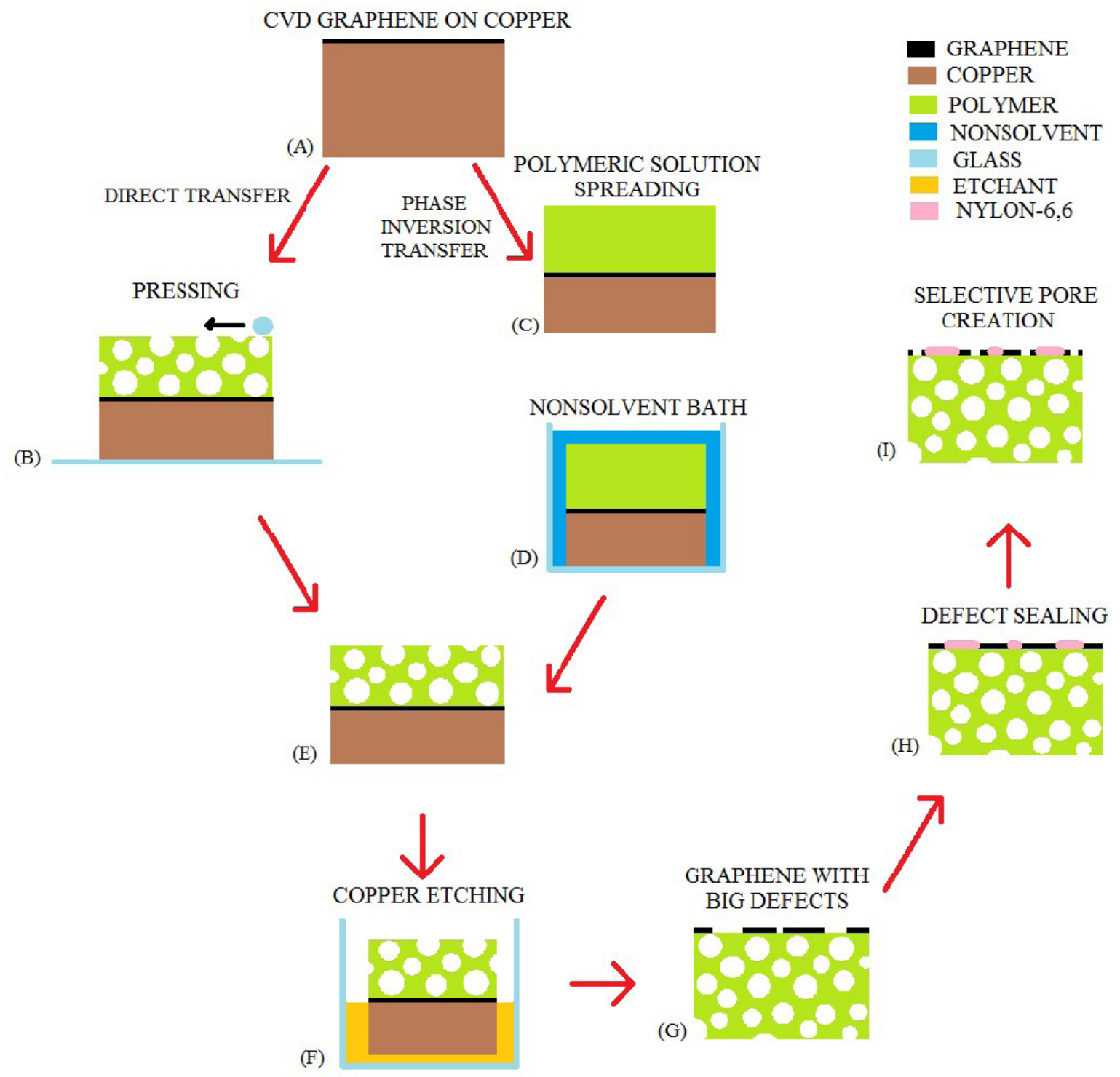

Figure 3: Process of synthesis of graphene membranes. Graphene obtained by chemical vapor deposition on a copper substrate $(\mathbf{A})$ receives on its free face a polymer that is fixed to it by light pressure between a plate and a glass rod (B), a method known as direct transfer. Or even, a polymeric solution of a polymer (C) that is subsequently immersed in a non-solvent bath (D), in order to generate the precipitation of the polymer on graphene, a method known as phase inversion. The Polymer / Graphene / Copper (E) system is then immersed in an etchant solution (F) which will cause copper to corrode. The membrane thus obtained $(\mathbf{G})$ has graphene with major defects from growth on copper or from the transfer method itself. These defects are usually sealed by interfacial polymerization of nylon-6,6 $(\mathbf{H})$ and, subsequently, appropriately sized, and controlled pores are created (I) using oxygen plasma, for example. Source: Authors

trade-off carried out by Robeson (1991) [22]. Finally, there is already experience in working with this polymer as an intermediate in the wet transfer of CVD graphene for the synthesis of membranes applicable to gas separation [50] and it is known that molecular weights greater than $495000 \mathrm{~g} / \mathrm{mol}$ are sufficient to promote adequate adhesion with graphene [30, 43].

Other examples of polymers that have already been used for the synthesis of graphene membrane supports are polycarbonate $[29,30,39,41,51]$, polypropylene
[38], polyvinylidene fluoride [38], polyethersulfone [52], polysulfone [40], poly(1-methylsilyl-1-propine) [53] and polydimethylsiloxane [50].

Another existing demand is that the support structure obtained can provide sufficient mechanical support for the graphene in the operating conditions $[47,54]$. The structure of the polymeric support can be of two types: symmetrical or asymmetric [47, 54]. Symmetrical supports have uniform pore distribution along their length $[47,54]$. Asymmetric ones have 
different pore sizes unevenly distributed in the material $[47,54]$. The asymmetric structure is commonly composed of a dense film of 0.1 to $2 \mu \mathrm{m}$, formed at the interface between the polymeric solution and the nonsolvent and a porous sublayer that is generally spongelike or finger-like $[47,54]$. Although attractive for many specialized applications, such as ultrafiltration and controlled drug delivery systems, structures with large finger-like pores are a problem in the case of membranes intended for high pressure applications such as gas separation and reverse osmosis [47, 54]. This is due to its large void volume and consequently low mechanical resistance $[47,54]$. The presence of a dense film on the surface of a graphene support for desalination is also not desirable, as it would reduce the flow of water and increase the pressure necessary for the operability of the membrane [47, 54]. Figure 4 shows the different possible morphologies for a polymeric support.

The polymer's morphology is determined by the conditions in which its synthesis was carried out, usually by phase inversion, and a thorough analysis of this step is necessary to obtain polymers with properties suitable for use as a support for graphene membranes [47, 54]. In addition to the different solvent/non-solvent combinations [40,54], other factors can influence the morphology of a polymer obtained by phase inversion, such as, for example, the drying method [55], exposure time to non-solvent [56], addition of non-solvent to the polymeric solution before the phase inversion [57], addition of surfactants [58-60] and addition of activated carbon [61].

As can be seen, for the synthesis of graphene membranes, in addition to all the concerns demanded by the traditional synthesis of polymeric membranes presented here, there are still several other stages of synthesis, such as growth of graphene, transfer of

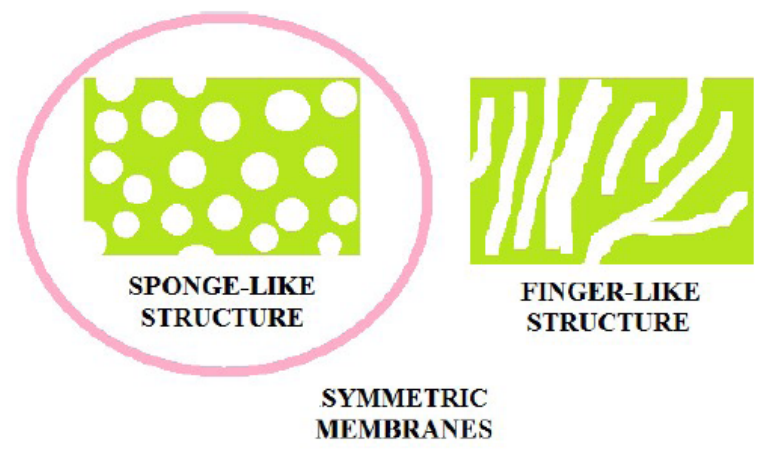

graphene to the polymer, copper etching, sealing the membranes and creating artificial pores. Each of these steps has its specificities and problems to be solved for graphene membranes to reach the market. In addition, this large number of steps is detrimental to the scaling up of the synthesis process of these membranes and will be an obstacle to their large-scale manufacture if it is considered that it will compete with much simpler and cheaper synthesis processes, such as productions of Loeb and Sourirajan and Thin Film Composites Membranes.

\section{APPLICATION OF GRAPHENE MEMBRANES FOR DESALINATION}

The scarcity of fresh water is one of the most worrying problems of the $21^{\text {st }}$ century and will be one of the greatest obstacles to the survival of humans soon [62]. Currently, five hundred million people live in conditions of severe and permanent water scarcity and four billion people live in these conditions for at least one month a year [62]. Population growth, industrialization, contamination of water resources and climate change tend to increase the challenge of producing drinking water in sufficient quantity and quality in the near future [63]. The search for technological solutions to increase the volume of available water becomes mandatory when the harmful consequences of inadequate water resources are recognized: decreased harvests and farmers' income, stoppage of companies that depend on water in their processes, loss of biodiversity and navigation difficulties in rivers with very low flows, among others [63].

Some measures to rationalize water consumption, such as smart land use planning, regional transfers of water resources, the construction of new dams and the modernization of collection and distribution methods need to be applied as primary solutions to scarcity [35,

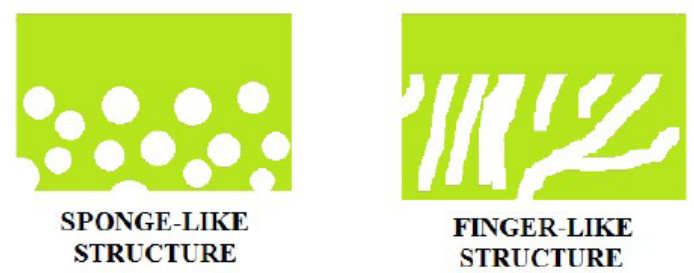

ASYMMETRIC MEMBRANES

Figure 4: Morphology of polymeric supports, highlighted within the pink circle the ideal morphology for the supports of graphene membranes. Source: Authors 
64]. However, even though these measures are necessary and must be applied, they are only able to improve the use of existing fresh water, and not to increase it $[64,65,66]$. So far, only two technologies, reuse, and desalination, have been able to accomplish this feat and reduce dependence on the hydrological cycle $[64,65,66]$. However, as they are more expensive, these actions are only recommended in countries that have already rationalized consumption and exhausted the possibilities of sophistication of operations carried out in natural fresh water sources $[35,64]$.

Desalination is the process of producing fresh water from saline water, that is, reducing the content of dissolved salts, usually in aqueous solutions with total salt concentrations around $36 \mathrm{~g} / \mathrm{L}$ (sea water), for concentrations below $0.5 \mathrm{~g} / \mathrm{L}$ [67]. Its main objective, corresponding to $59 \%$ of the installed capacity, is to take advantage of the potential of fresh water supply via ocean water processing [67]. In addition to having an abundant amount, equivalent to $97.5 \%$ of all water on the planet, these waters are still located close to places of consumption, given that almost half of the world's population lives less than $100 \mathrm{~km}$ away from an ocean $[64,65,68]$. The other applications of desalination include the treatment of brackish water $(22 \%)$ and rivers $(9 \%)$, wastewater reuse $(5 \%)$ and special applications $(5 \%)[64,65,68]$.

The desalination market has been growing over the years [65]. In 2013, the cumulative global capacity of desalination plants was 85.9 million $\mathrm{m}^{3} /$ day, compared to 52.8 million $\mathrm{m}^{3} /$ day in 2008 and 5 million $\mathrm{m}^{3} /$ day in 1980 [65]. The most used desalination methods are multi-stage flash distillation, multiple effect distillation, reverse osmosis, electrodialysis, reverse electrodialysis, freezing, solar evaporation, direct osmosis, membrane distillation, as well as humidification and dehumidification [65].

Among the desalination technologies, the first to be applied on a large scale were those based on thermal desalination (multi-stage flash distillation and multiple effects distillation) used in the construction of plants in Gulf countries, some of which are still in operation [35, 63]. These plants, because they are based on the heating of sea water and subsequent condensation to produce fresh water, consume a large amount of thermal energy and, as a result, emit significant volumes of greenhouse gases, in addition to suffering on a large scale from the effects of corrosion [35, 63]. As a result of these problems, currently $65 \%$ of operations are based on separation by reverse osmosis, the most energy-efficient technology for both the desalination of brackish and sea waters and for the recovery of wastewater [67]. Due to its predominance in the market, this method is used as a baseline in comparison with any emerging desalination technique [67].

A typical reverse osmosis seawater desalination plant consists of an intake facility that guarantees a continuous water supply; a pre-treatment step that includes filtration and coagulation to remove large particles and solids, avoiding incrustation on the membrane surface; reverse osmosis, the main stage of the separation process, coupled to a unit for recovering the energy from pressurized fluids; post-treatment, which includes the introduction of additives, such as important minerals that were removed during the process, in order to make the water palatable and noncorrosive, disinfection and removal of unwanted substances that can pass through the membrane (boron, for example); and a brine discharge system [63, $65,68]$.

The understanding of the basis of the reverse osmosis separation process involves the following observation: if two solutions, under the same conditions, with different concentrations of the same solute are separated by a barrier preferably permeable to the solvent, the natural tendency is for this solvent to pass through barrier, leaving the least concentrated solution towards the most concentrated solution until the concentrations are equal [64, 69]. This phenomenon, known as osmosis, occurs due to the difference in chemical potential between the solutions $[64,69]$. The osmotic pressure can then be defined as the minimum pressure that must be imposed on the most concentrated solution so that the osmotic process does not occur $[64,69]$. And reverse osmosis can consequently be determined as the process in which a pressure higher than the osmotic pressure is applied to the most concentrated solution in order to reverse the solvent flow, that is, to cause a solvent flow to abandon the most concentrated solution towards the less concentrated solution $[64,69]$.

In the industry, when the osmotic pressure is raised, selective water permeation through a semipermeable membrane is possible, forming a stream that is called permeate, and retaining a more concentrated saline solution, called concentrate, performing the separation [67]. The ratio between the permeate flow rate and the feed flow rate is called recovery and is commonly set at 
$50 \%$ [67]. For this recovery, it is known that the osmotic pressure of sea water increases from 28 bar in the feed to 56 bar in the concentrate, making an operational pressure of 61 to 68 bar necessary and requiring a high pressure pump [67]. The use of this equipment justifies the fact that reverse osmosis is the point in the process where the largest amount of energy is consumed, with values varying between $70 \%$ and $90 \%$ of the total energy of the operation $[63,65,68]$.

There are concerns about the environmental impacts of large reverse osmosis plants, but the widely accepted view is that the effects are not prohibitive, provided that appropriate measures are taken from the moment of implementation [63]. Some examples can be mentioned, such as operation with low suction speed, use of suitable grids, installation in regions of low biological productivity and construction of efficient concentrate diffuser systems [63].

Although advances in technology and equipment for energy recovery and reuse applied to desalination have resulted in an $80 \%$ reduction in the energy used in water production in the last 20 years, the real obstacle to the expansion of reverse osmosis remains its high energetic consumption [66]. Although more efficient than thermal desalination, energy is still responsible for 30 to $50 \%$ of the costs of water desalinated by reverse osmosis, on average $1.1 \mathrm{US} \$ / \mathrm{m}^{3}$ [66]. As a result, most reverse osmosis desalination plants in large urban areas of the world provide only a small portion of the total drinking water demand that typically ranges between 5 and $20 \%$ [65].

While the complete multi-stage flash distillation process consumes an average of $15.5 \mathrm{kWh} / \mathrm{m}^{3}$ and the multiple effect distillation $7.5 \mathrm{kWh} / \mathrm{m}^{3}$, the theoretical value in a reversible reverse osmosis process of seawater with total concentration of $35 \mathrm{~g} / \mathrm{L}$ of salts is $1.06 \mathrm{kWh} / \mathrm{m}^{3}$ for $50 \%$ recovery [63]. For a full-scale operation, due to irreversibility, the practical energy expenditure only in the reverse osmosis stage varies between 2.5 and $4.0 \mathrm{kWh} / \mathrm{m}^{3}$, while the intake, pretreatment and post-treatment stages add together between $0.5 \mathrm{kWh} / \mathrm{m}^{3}$ and $1 \mathrm{kWh} / \mathrm{m}^{3}$ [68]. For comparison, the use of energy for conventional freshwater treatments reaches a maximum of 0.4 $\mathrm{kWh} / \mathrm{m}^{3}$ [68]. The analysis of these values indicates that the energy required for the desalination of sea water, even for reverse osmosis, which is the leading method in the current scenario, varies between eight to thirteen times that of the production of fresh water from conventional sources, such as rivers, lakes, and aquifers, continuing to be currently the alternative with the highest energy expenditure for the production of drinking water $[65,66]$.

Having presented the importance of reducing energy consumption in reverse osmosis, the search for solutions becomes mandatory for the evolution of the technique $[63,66]$. Some important steps in the process need to be studied carefully to identify improvements that can be implemented, such as the installation of energy recovery devices, changes in layout, the use of larger and more efficient pumps and the improvement of membrane modules $[63,66]$. Technological advances throughout the process are expected to reduce the cost of desalinated water by $20 \%$ over the next 5 years and by up to $60 \%$ over the next 20 years $[63,66]$.

From the knowledge of the seawater desalination process by reverse osmosis, the question arises about the possibility of developing more energy efficient membrane modules, maintaining, or overcoming the reliability and low environmental impact of those available on the market $[63,64,66,68]$. The main change that would allow to achieve, even partially, the necessary increase in the efficiency of the modules would be the construction of membrane elements of high productivity and low energy consumption $[63,64$, $66,68]$.

Semipermeable membranes composed solely of polymeric materials and capable of producing fresh water from seawater are the most important element of reverse osmosis desalination since the first operation $[35,63]$. The current membranes, supplied by the main manufacturers, are based on a discovery of the 1980s, the interfacial polymerization of monomeric aromatic amines generating thin polyamide film $[35,63]$.

Interfacial polymerization consists of the union, without agitation, of immiscible phases containing complementary reagents dissolved in solvents unable to solubilize the polymer produced in the polymerization reaction [70]. For the synthesis of polyamide, for example, the reagents can be $\mathrm{m}$ phenylenediamine dissolved in water and trimesoyl chloride dissolved in organic solvent [70]. The reaction carried out under these conditions is usually fast and from it a thin layer of polymer is synthesized at the interface between the two phases, this technique being used to manufacture thin film reverse osmosis membranes [70]. The advantages of membranes from this process include high permeability and selectivity 
(compared to other polymeric membranes) due to the low thickness of the selective film and lower costs, since simpler polymers can be used to make the support that represents the largest volume of membrane and does not need to have selective properties [70]. In addition, this process minimizes the chance of finger-like porosity occurring which would decrease the physical resistance of the thin film [70]. However, interfacial polymerization usually presents the problem of producing polymers with a large molecular weight distribution, which makes them unsuitable for making hollow fibers [8].

Analyzing specifically the polyamide thin film membranes, they consist of a dense semi-permeable film matrix randomly structured from polyamide $(0.25$ $\mu \mathrm{m}$ thickness), which is placed over a porous polysulfone intermediate layer $(50 \mu \mathrm{m}$ thick, pores with $0.0325 \mu \mathrm{m}$ of medium diameter), supported on a polyester (125 $\mu \mathrm{m}$ thickness) [63]. In these membranes, the low thickness of their selective layer provides good water permeability, $3.5 \times 10^{-12} \mathrm{~m}^{3} \mathrm{~m}^{-2} \mathrm{~Pa}^{-1}$ $\mathrm{s}^{-1}$ [63]. Polyester allows the barrier to resist compression when exposed to high pressures and the porous structure of the intermediate layer ensures that the thin layer of polyamide will not come off during use [71]. Polyamide/polysulfone/polyester membranes also have good chemical stability, withstanding $\mathrm{pH}$ variations in the range of 3 to 11 and temperatures around $50{ }^{\circ} \mathrm{C}$, conditions used in some cleaning procedures [71]. Currently typical 8" membrane modules combining productivity of $55 \mathrm{~m}^{3} /$ day of fresh water and saline rejection of $99.8 \%$ are commercially available, compared to productivity of 34 and 22 $\mathrm{m}^{3} /$ day and rejections of 99.7 and $99.6 \%$ in 2004 and 1990 respectively $[35,66]$.

Despite having dominated the market, these membranes present some problems [63]. As an example, it has not yet been possible to successfully produce them in the form of hollow fibers [63]. In addition, its surface (angle of contact with water: $60^{\circ}$, mean square roughness: $200 \mathrm{~nm}$ ) tends to undergo bio-incrustation, that is, growth of microorganisms on the membrane surface that reduces the process performance [63]. These microorganisms could be eliminated by adding chlorine, however, the polyamide has an amide bond and unprotected aromatic rings that are susceptible to attack by chlorine and other oxidizing agents $[64,66,68,72,73]$. It can also be mentioned that, because it is a dense film, transport is relatively inefficient, requiring substantial energy to move water molecules through these membranes $[64,66,68,72$,
73]. Other problems include the low recovery that results in the need to feed the system with large volumes of water, increasing the costs of suction, pretreatment and producing an excessive amount of concentrated brine and the inefficient removal of low molecular weight contaminants, mainly the boron [64, $66,68,72,73]$.

Membranes with greater permeability to water and greater rejection of boron (currently the best membrane, in this regard, available on the market has only $93 \%$ boron rejection) need to emerge as an alternative to polyamide membranes [35]. The greater permeability would reduce the required pumping pressure and proportionally the energy demand to generate reasonable water flows, provided that the minimum energy limit necessary to overcome the osmotic pressure inherent in the concentrate that leaves the process was exceeded [63, 67]. Similarly, moving boron concentrations to levels tolerated by agricultural plantations would alleviate after-treatment requirements, which would also lead to decreased energy and capital costs $[63,67]$.

Although the productivity of the modules has increased significantly in recent years, this is due more to the increase in the membrane area per module than to advances in the membranes [35, 63, 67]. Advances in properties such as the permeability of membranes prepared solely from polymeric materials have been rather slow and limited since the late 1990s and appear to be approaching stagnation [35, 63, 67]. It seems necessary to change the separation mechanism, since the current one, because it is based only on the diffusion of the solution in the polymeric matrix, links the permeability increases to the selectivity reductions $[35,63,67]$.

The emergence of membranes with a low tendency to suffer a wide range of incrustations is also indispensable $[35,63,64]$. These characteristics would reduce the demands of the pre-treatment stage and the chemical cleaning as well as the excessive pressure to overcome the resistance that arises when the membranes become incrusted $[35,63,64]$. Consequently, energy consumption and capital cost of industrial plants would decrease [35, 63, 64]. Hydrophilic and low-roughness surfaces need to be synthesized in order to induce the formation of a thin layer of water in contact with the membrane during use $[35,63,64]$. This layer would act as a barrier to adhesion and promote the desired incrustation resistance $[35,63,64]$. It is worth mentioning that the 
majority of polymers, with satisfactory chemical and mechanical stability, currently used in the manufacture of membranes for this application, are hydrophobic [35, $63,64]$.

Materials with high resistance to oxidation, mainly by chlorine, the most economical disinfectant, are also essential and should be included in the next generation of membranes. As already mentioned, the most sensitive points to chlorine in commercially successful membranes are the amide bonds and aromatic rings [72]. When exposed to chlorine, these groups generally undergo reactions that can cause deformation of the polymeric chain or cleavage of bonds causing permanent membrane failure and reduced saline rejection [72]. Functional groups associated with lone pairs of electrons allow the formation of hydrogen bonds with water molecules, being important for hydrophilicity and to facilitate the transport of liquid [72]. In this way, there are attempts to prepare membranes with tertiary amide bonds, functional oxygen or sulfur groups, replacing the secondary amide group, to improve chlorine resistance without increasing hydrophobicity [72]. Ring structures of five or six carbon atoms usually provide optimal structural characteristics necessary for the formation of voids with hydrophilic contours of molecular size that facilitate the passage of water [72]. Thus, materials that have aromatic rings and at the same time are inert to chlorine are strong candidates for the composition of the membranes of the future [72].

In thin film polyamide membranes, water transport is governed by a water diffusion mechanism in the dense and highly cross-linked polymer, characteristics necessary to obtain high salt rejection [30]. The basis of the concept of diffusion separation is that the permeate species preferentially dissolve in the polymeric material and diffuse slowly through it, as a result of concentration and pressure gradients [30]. In contrast, in the pore flow mechanism, the membrane material is ideally not an active participant at the molecular level, and the separation is based on the existence of small pores that can be used as filters based on size, since small species (such as water, diameter $0.3 \mathrm{~nm}$ ) can pass through them, while larger species (such as sodium chloride, average hydrated ion diameter of $0.7 \mathrm{~nm}$ ) cannot [30]. When the separation is governed by this mechanism, the flow rate is a function of $D^{4} / L$ for a cylindrical pore of diameter $D$ and length $L$, that is, it increases with decreasing length [30]. It is likely, therefore, that new desalination technologies may be based on thin nanoporous membranes, which, with well-defined channels, would allow a faster flow of water than on thin film membranes, maintaining saline rejection [39, $64,66,73,74]$.

Membrane modules with spiral configuration have been the ones that have best adapted to the characteristics of thin film polyamide membranes [63, 75]. In this arrangement, the feed is inserted into the outer surface of flat membranes wrapped around a tube, through which the permeate is removed $[63,75]$. However, it is expected that developers of new technologies in the field of reverse osmosis desalination will search for materials that can be formed into more effective configurations [63, 75]. An example would be the configuration of hollow fibers, where the feed is injected into a module containing hundreds to millions of membranes in a very small diameter cylindrical shape, in the order of $200 \mu \mathrm{m}$, so that the permeate is transported out cylinders and the concentrate is retained inside [75]. This configuration would offer greater packing density (up to 16,400 $\mathrm{m}^{2} / \mathrm{m}^{3}$ compared to $820 \mathrm{~m}^{2} / \mathrm{m}^{3}$ for the spiral configuration), and consequently greater active surface, productivity and energy efficiency, maintaining the module's diameter [75]. In addition, its applicability in full-scale desalination plants has already been demonstrated, with cellulose acetate membranes, which were the majority in the market before the insertion of thin film polyamide membranes, in the 1980s [63].

Advances in materials science will offer the possibility of obtaining membranes for reverse osmosis that meet some of these demands (increased permeability without decreasing saline rejection, increased selective rejection of specific compounds, increased resistance to oxidation by chlorine and other oxidizing agents, increase in hydrophilicity, suitability for hollow fiber configuration, separation mechanism based on pore size, reduction of incrustation rates) [28, $35,67]$. These changes will be possible through the development of membranes from aquaporins, zeolites, carbon nanotubes or graphene in a period of more than 5 years, all with the potential to cause energy improvements of up to $0.5 \mathrm{kWh} / \mathrm{m}^{3}$, that is, something between 10 and $20 \%$ reduction in energy consumption of the desalination operation $[28,35,67]$. If they reach their full potential, nanostructured membranes can produce, using the same surface area, up to 20 times more fresh water than the membranes available on the market today and reduce the physical size and construction costs of plants by a factor of two [66]. 
Computationally, it has already been shown that graphene would be able to effectively separate sodium chloride from water in concentrations of $72 \mathrm{~g} / \mathrm{L}$ and pressures from 1000 to 2000 bar (unrealistic values, but necessary for the simulation and with results applicable to the operating conditions) [28]. For this, it would be necessary to create an artificial porosity of about $10 \%$ in its structure [28]. The graphene membrane in this case would have water permeability of up to $1.2 \times 10^{-8} \mathrm{~m}^{3} \mathrm{~m}^{-2} \mathrm{~Pa}^{-1} \mathrm{~s}^{-1}$ with saline rejection up to three orders of magnitude greater than thin film membranes (permeability: $3.5 \times 10^{-12} \mathrm{~m}^{3} \mathrm{~m}^{-2} \mathrm{~Pa}^{-1} \mathrm{~s}^{-1}$, saline rejection: $99.8 \%$, previously presented) [28]. The results also indicate that not even water molecules are able to permeate defect-free graphene, with natural pores of $0.34 \mathrm{~nm}$ [28]. However, if artificial pores are created with a diameter greater than $0.50 \mathrm{~nm}$, most salt ions can permeate it [28].

From the computational evidence of the efficiency of graphene membranes for desalination, some experimental studies, presented in Table 1, were carried out aiming to synthesize these membranes.

Transport through a layer of CVD graphene has been investigated experimentally (area: $25 \mathrm{~mm}^{2}$, average roughness: $185 \mathrm{~nm}$, porosity due to intrinsic defects resulting from failures in the CVD process: $0.012 \%$, range of greatest concentration of pore diameters: 0 to $15 \mathrm{~nm}$ ) [30]. Graphene was grown in copper foil (thickness: $25 \mu \mathrm{m}$, average roughness: 500 $\mathrm{nm}$, purity: 99.8\%) [30]. The graphene sheet was transferred directly to a polycarbonate support (average pore diameter: $200 \mathrm{~nm}$, average pore length: $10 \mu \mathrm{m})$ followed by copper etching by ammonium persulfate (concentration: 10\% w/w) [30]. In the best result, it was possible to cover up to $98 \%$ of the polymeric area with graphene and a $54 \%$ less potassium chloride flow was obtained when compared to the support without graphene [30]. The theoretical decrease in flow would be $90 \%$ if the graphene sheet had no defects greater than $50 \mathrm{~nm}$ and $100 \%$ if it had no defects [30].

Continuing this study, the same procedures and materials were used for the synthesis of new graphene membranes [39]. In this new study, in addition to the intrinsic defects (diameters: 1 to $15 \mathrm{~nm}$ ), large extrinsic defects (diameters: 100 to $200 \mathrm{~nm}$ ) arising from the transfer procedure to the polymeric support are reported [39]. The intrinsic defects were sealed with a film (thickness: $3.5 \mathrm{~nm}$ ) of hafnium oxide $\left(\mathrm{HfO}_{2}\right)$ while the large defects were sealed with hafnium oxide and nylon-6.6 generating potassium chloride flows $60 \%$ and $92 \%$ smaller than that through of the polymer without graphene after the respective seals [39]. Only $42 \%$ of sealed graphene was available for use as a membrane and further reductions in flows could occur at the expense of additional decreases in the active area of graphene [39]. Subsequently, pores (density $3.89 \times 10^{13}$ $\mathrm{cm}^{-2}$, mean diameter $0.162 \mathrm{~nm}$ ) were introduced into the graphene using gallium ions beams [39]. The membrane thus obtained, showed a permeability of $3.9 \times 10^{-12} \mathrm{~m}^{3} \mathrm{~m}^{-2} \mathrm{~Pa}^{-1} \mathrm{~s}^{-1}$, that is, the same order of magnitude as the current commercial reverse osmosis membranes, in addition, it presented magnesium sulfate flow (mean diameter of hydrated ions of $0.9 \mathrm{~nm}$ ) $70 \%$ less than that through graphene-free polycarbonate [39]. However, the flow of sodium chloride (average hydrated ion diameter of $0.7 \mathrm{~nm}$ ) to the membrane was greater than that through the support without graphene, indicating that the creation of large pores occurred and that the interactions inside pores facilitated the transport of monovalent ions [39].

Table 1: Experimental Studies on the Application of Graphene Membranes to Desalination. Source: Authors

\begin{tabular}{|c|c|c|c|c|}
\hline System & Graphene Area & Polymeric Support & Transfer Method & Reference \\
\hline $\mathrm{KCl} / \mathrm{H}_{2} \mathrm{O}$ & $25 \mathrm{~mm}^{2}$ & Polycarbonate & Direct transfer & [30] \\
\hline $\begin{array}{c}\mathrm{MgSO}_{4} / \mathrm{H}_{2} \mathrm{O} \\
\mathrm{NaCl} / \mathrm{H}_{2} \mathrm{O}\end{array}$ & $25 \mathrm{~mm}^{2}$ & Polycarbonate & Direct transfer & [39] \\
\hline $\mathrm{MgSO}_{4} / \mathrm{H}_{2} \mathrm{O}$ & $1 \mathrm{~cm}^{2}$ & Polycarbonate & Direct transfer & [41] \\
\hline $\mathrm{KCl} / \mathrm{H}_{2} \mathrm{O}$ & $1 \mathrm{~cm}^{2}$ & Polycarbonate & Direct transfer & [29] \\
\hline $\mathrm{KCl} / \mathrm{H}_{2} \mathrm{O}$ & $1 \mathrm{~cm}^{2}$ & Polypropylene, Polyvinylidene fluoride & Direct transfer & [38] \\
\hline $\begin{array}{c}\mathrm{NaCl} / \mathrm{H}_{2} \mathrm{O} \\
\mathrm{MgSO}_{4} / \mathrm{H}_{2} \mathrm{O}\end{array}$ & $63 \mathrm{~cm}^{2}$ & Polyethersulfone & Phase inversion & {$[52]$} \\
\hline $\mathrm{KCl} / \mathrm{H}_{2} \mathrm{O}$ & $31,5 \mathrm{~cm}^{2}$ & Polysulfone & Phase inversion & {$[40]$} \\
\hline
\end{tabular}


In another work on the same line, a CVD graphene monolayer (area: $1 \mathrm{~cm}^{2}$ ) covering $95 \%$ of the copper substrate area (thickness: $18 \mu \mathrm{m}$ ) in which it was grown, was transferred by direct transfer to a polycarbonate support (diameter: $25 \mathrm{~mm}$, average pore diameter: $200 \mathrm{~nm}$ ) previously treated with dodecyl amine to increase hydrophobicity [41]. Subsequently, copper was removed using ammonium persulfate etchant and the major defects were sealed by nylon- 6.6 interfacial polymerization. A high density of nanopores (diameters: < $2 \mathrm{~nm}$; porosity: $10^{13} \mathrm{~cm}^{-2}$ ) was also created using gallium ions beams and oxygen plasma [41]. A pore area between 4 and $5 \%$ of the total membrane area was reached (percentage of waterpermeable pores: $45.24 \%$ ). The result was a membrane with a permeability of $3.6 \times 10^{-11} \mathrm{~m}^{3} \mathrm{~m}^{-2} \mathrm{~Pa}^{-1}$ $\mathrm{s}^{-1}$ and a $98 \%$ decrease in the flow of magnesium sulfate compared to the flow through polycarbonate [41].

Still using polycarbonate as a support (porosity: 10\%, thickness: $10 \mu \mathrm{m}$, average pore diameter: 200 $\mathrm{nm}$ ), in another study, graphene sheets (area: $1 \mathrm{~cm}^{2}$ ) from the CVD process on a substrate of copper (thickness: $18 \mu \mathrm{m}$; purity: 99.9\%) were transferred [29]. Next, copper etching was carried out using ammonium persulfate, sealing of defects again by nylon-6,6 and soon after, artificial pores were created, using oxygen plasma (diameters: < $4 \mathrm{~nm}$, range of greater concentration of diameters pore size: 0 to $1 \mathrm{~nm}$ ) to obtain dialysis membranes [29]. The resulting membranes showed an increase in permeability of up to two orders of magnitude compared to commercial dialysis models [29].

There is a report of an experimental study of CVD graphene transfer (area: $1 \mathrm{~cm}^{2}$ ), grown on copper foil (thickness: $25 \mu \mathrm{m}$ ) to commercial polypropylene microfiltration membranes (thickness: $75 \mu \mathrm{m}$, average pore diameter: $100 \mathrm{~nm}$, mean square roughness: 42.4 $\mathrm{nm}$, contact angle: $115^{\circ}$ ) and polyvinylidene fluoride (thickness: $20 \mu \mathrm{m}$, mean pore diameter: $20 \mathrm{~nm}$, mean square roughness: $23.8 \mathrm{~nm}$, contact angle: $90^{\circ}$ ) [38]. After the direct transfer procedure, copper was removed using ammonium persulfate solution (concentration: $5 \% \mathrm{w} / \mathrm{w}$ ) [38]. The obtained polypropylene graphene membrane blocked $57 \%$ of the potassium chloride flow (concentration: $0.5 \mathrm{~mol} / \mathrm{L}$ ) compared to the flow through the polymer alone, and the sealing of defects using nylon-6.6 increased this block to $84 \%$ [38]. The graphene sheet supported by polyvinylidene fluoride blocked $40 \%$ of the potassium chloride flow, increasing to $67 \%$ after sealing with nylon-6,6, again comparing with the flow through the isolated polymeric support [38]. The better performance of the polypropylene support was attributed to its greater hydrophobicity [38].

The growth of CVD graphene (area: $63 \mathrm{~cm}^{2}$ ) on copper substrate has already been tested, followed by phase inversion transfer to polyethersulfone support (thickness: $100 \mu \mathrm{m}$; porosity: 35\%) [52]. The transfer was made by solubilizing the polymer (concentration: $20 \% \mathrm{w} / \mathrm{w}$ ) in N-methylpyrrolidone, distribution under the graphene surface and subsequent immersion in water [52]. Polyethersulfone with 3 layers was obtained: the first ultra-thin layer bound to graphene (thickness: 500 $\mathrm{nm}$, pore diameter: $50-500 \mathrm{~nm}$ ), the second layer with finger-like pores (average pore diameter: $3 \mu \mathrm{m}$, density pore size: $4.5 \times 10^{6} \mathrm{~cm}^{-2}$ ) and the third microporous layer [52]. Then, copper was dissolved using ammonium persulfate. The result was a surface with little water permeability (defect area: $<0.003 \%$ or $<1$ $\mu \mathrm{m}^{2}$, defect diameter: $<300 \mathrm{~nm}$ ). The sealing was performed by filtration of an aqueous suspension of polystyrene nanoparticles (particle diameter: $1 \mathrm{~nm}$ to 2 $\mu \mathrm{m})$ [52]. The sealed structure withstood 50 bar of pressure without breaking and, even with this high pressure, it was impermeable to water [52]. In order to obtain a nanofiltration membrane, gallium ions beams were used to create artificial pores (average pore diameter: $1 \mathrm{~nm}$, water-permeable pore density: $1.57 \times 10^{12} \mathrm{~cm}^{-2}$ ) [52]. The result was a membrane with a permeability of $1.4 \times 10^{-10} \mathrm{~m}^{3} \mathrm{~m}^{-2} \mathrm{~Pa}^{-1} \mathrm{~s}^{-1}$, five times greater than that of polymeric nanofiltration membranes, with high rejection of molecules greater than $1 \mathrm{~nm}$ [52]. For species with a hydrated diameter less than $1 \mathrm{~nm}$, such as sodium chloride and magnesium sulfate, enrichment is observed instead of rejection, this phenomenon being attributed to the high diameter of the pores and the interactions within the pores of graphene [52]. To analyze the tendency to suffer bio-incrustation, the membrane was exposed to Escherichia coli suspension $\left(10^{7}\right.$ colony-forming units $/ \mathrm{mL}$ ) for 5 hours and no colonies were observed [52]. The repetition of the experiment with a commercial membrane generated several colonies [52].

Phase inversion transfer of CVD graphene (dimensions: $7 \mathrm{~cm} \times 4.5 \mathrm{~cm}$, mean roughness: 9.58 $\mathrm{nm}$ ) synthesized on copper sheets to polysulfone polymer support (molar mass: $35000 \mathrm{~g} / \mathrm{mol}$ ) has also been studied [40]. The phase inversion occurred by dissolving the polysulfone in $\mathrm{N}$-methylpyrrolidone (concentration: $20 \% \mathrm{w} / \mathrm{w}$ ) followed by immersion in 
ethanol (concentration: 94.5\%) or water [40]. Sequentially, ammonium persulfate etching was carried out (concentration: 10\% w/w) [40]. The best result, using ethanol as a non-solvent, was a graphene membrane supported by polysulfone (10 $\mu \mathrm{m}$ thick) in which unintended defects were limited, with medium roughness $(11.16 \mathrm{~nm})$ close to that of the graphene sheet supported by copper [40]. Transport measures for this membrane showed a potassium chloride flow block (concentration: $0.5 \mathrm{~mol} / \mathrm{L}$ ) of $99.5 \%$ compared to polysulfone without graphene and impermeability to water up to a pressure of 20 bar [40].

The studies reported so far show that there have been major advances in the synthesis of graphene membranes with polymeric supports for desalination, but that the technology is still far from approaching its computationally predicted potential [28]. The main challenge remains to expand the area of the CVD graphene monolayers produced, still limited to square centimeters, however, the development of new transfer methods and improved supports, which minimize the generation of defects, is also still necessary.

The main impetus for carrying out future studies will come from the excellent properties presented by these membranes, which can significantly decrease the energy expenditure of the desalination process and the costs of desalinated water, a fundamental resource for human survival in a world with increasing scarcity of fresh water. As seen, several experimental studies with these membranes have achieved permeability higher than that of polymeric membranes for the same applications [29, 41, 52], needing only to improve selectivity to present a performance far superior to that of these membranes, which is likely according to the results presented by the computer simulation [28]. With the improvement of the pore creation and passivation technique, graphene membranes will be able to separate low molecular weight compounds from water, due to intermolecular forces with specific functional groups inside the pores, which is not yet possible using traditional polymeric membranes. The graphene membrane will also show high resistance to disinfectants, thanks to the chemical stability of the material, the low tendency to suffer bio-incrustations [52] and the high resistance of graphitic carbon to chlorine $[36,76]$, which will facilitate cleaning and avoid the reduction of flow by fouling, which affects polymer membranes on a large scale. Finally, although the area of the membranes synthesized until then was too small to think of configurations different from the planar configuration, the good properties of graphene indicate that, with the proper technique and support, in the future it will be possible to obtain graphene membranes in hollow fibers, the most efficient configuration for a membrane module.

\section{APPLICATION OF GRAPHENE MEMBRANES FOR GAS SEPARATION}

\subsection{Potential Gas Mixtures To Be Separated}

\subsubsection{Carbon Dioxide/Nitrogen}

The greenhouse effect is a natural phenomenon in which some gases present in the atmosphere $\left(\mathrm{CO}_{2}\right.$, $\mathrm{CH}_{4}$ and $\mathrm{H}_{2} \mathrm{O}$, for example) absorb the infrared radiation reflected by the planet's surface, controlling the Earth's temperature. However, in recent times, the concentration of these gases in the atmosphere is increasing rapidly and, consequently, the greenhouse effect as well. The intensification of this effect causes a series of environmental problems, such as an increase in global temperature (an increase of up to $5.8^{\circ} \mathrm{C}$ is estimated by 2100), changes in ecosystems and the rain cycle, loss of biodiversity, reduction in crops and sea level rise $[77,78,79]$.

Fossil fuels such as methane, because they are cheap, are used to produce $85 \%$ of the energy consumed for industrial activities in the world and are responsible for $40 \%$ of the world's carbon dioxide emissions $[77,78,80]$. This places the burning of fossil fuels as the main cause of the increase in the concentration of greenhouse gases in the atmosphere, being responsible for $55 \%$ of global warming [77, 78, $80]$. There are possible measures to be taken to reduce the speed of anthropological global warming, such as improving the energy efficiency of the processes and the greater use of non-fossil fuels. In addition, as shown below, some gas separation processes are of significant importance in the control of this environmental problem [79].

The carbon dioxide capture in plants producing energy from gas or coal followed by storage in an appropriate location is still in a pilot stage, but is an alternative that shows potential to reduce atmospheric emissions from energy by up to $20 \%$ and limit climate change, at the cost of an increase of up to $10 \%$ in the price of energy produced [80].

The capture process consists of separating $\mathrm{CO}_{2}$ from gas mixtures (such as natural gas or combustion gases), pressurizing at 70 bar, transporting liquefied carbon dioxide and, finally, injecting the fluid into pores 
of rocks located about $800 \mathrm{~m}$ below the surface [80]. In this way, the gas that would be released directly into the atmosphere is stored underground, reducing the unwanted effects of its emission [81].

Among the stages of carbon dioxide capture, the separation of it from the gas mixture, currently carried out by absorption with amine solvents, is the one with the highest energy consumption, being responsible for $70 \%$ of the operation costs $[80,82]$. Other absorption problems worth mentioning are the demand for a very large installation, comparable to the size of the power plant itself, and the use of very large volumes of solvents [80]. There are other methods of separating $\mathrm{CO}_{2}$ from gas mixtures, such as physical absorption, pressure and temperature swing absorption, cryogenic distillation, and membrane separation, however, in the current stage of technologies, absorption by amine solvents is the most efficient method, despite to present many problems as already reported [79]. This makes $\mathrm{CO}_{2}$ capture a possible but still inefficient process [80]. Therefore, the progress of $\mathrm{CO}_{2}$ separation technologies for both $\mathrm{CH}_{4}$ (for processes that use natural gas as an energy source) and $\mathrm{N}_{2}$ (for separating $\mathrm{CO}_{2}$ from the flue gases) is necessary for the capture $\mathrm{CO}_{2}$ develop its full potential and help to slow climate change. The improvement of the carbon dioxide capture technology can have an even greater positive environmental impact if it becomes efficient to enough to be extended beyond the power plants, reaching refineries, steel mills, fertilizer, ethanol fermentation and cement plants [80]. In this scenario, the United States Department of Energy identified membranes as one of three basic research needs for carbon capture separation processes $[8,83]$. The next two subsections present the current state of the technology for separation by polymeric membranes of the mixtures $\mathrm{CO}_{2} / \mathrm{N}_{2}$ and $\mathrm{CO}_{2} / \mathrm{CH}_{4}$.

Combustion gases emitted in large quantities in industries such as power generation usually have a carbon dioxide content of around $15 \%$ and polymeric membranes could become a low-cost alternative for the separation of $\mathrm{CO}_{2} / \mathrm{N}_{2}$ in these gases [79]. Polycarbonates, polysulfones and polyimides are examples of polymers with good performance for $\mathrm{CO}_{2} / \mathrm{N}_{2}$ separation [79]. Among these polymers the most prominent is the polyimide due to its good physical properties, gas transport and simple synthesis [79]. However, all these polymers have some problems, such as the fact that they cannot withstand the high temperatures of the flue gases, requiring them to be cooled below $100{ }^{\circ} \mathrm{C}$ before separation [79]. In addition, these gases also usually present aggressive compounds to membrane materials, such as particulate materials, acidic and oxidizing compounds $\left(\mathrm{SO}_{2}, \mathrm{No}_{x}\right.$, $\mathrm{HCl}$, etc.) [79]. It is worth mentioning that, due to the low concentration of $\mathrm{CO}_{2}$ in the post-combustion gases, membranes with very high $\mathrm{CO}_{2} / \mathrm{N}_{2}$ selectivity need to be synthesized for the membrane separation process to become competitive [8].

\subsubsection{Carbon Dioxide/Methane}

Carbon dioxide is a component of natural gas - the cleanest, safest, and most efficient commercial fossil fuel - of anaerobic digesting biogas and landfill gas [81]. In these mixtures, the $\mathrm{CO}_{2}$ concentration varies between 0.06 and $42.66 \%$, while the concentration of methane, its main component, varies between 29.98 and $90.12 \%$ [84]. Unlike the $\mathrm{CO}_{2} / \mathrm{N}_{2}$ separation, the $\mathrm{CO}_{2} / \mathrm{CH}_{4}$ separation is mandatory not only for the environmental aspect, since the removal of carbon dioxide, as well as other acid gases $\left(\mathrm{H}_{2} \mathrm{~S}, \mathrm{SO}_{2}\right)$ generates fuels with greater calorific power, lower volumes to be transported, in addition to reducing corrosion in gas transport systems [81]. Gas pipelines for natural gas, for example, typically require $\mathrm{CO}_{2}$ concentrations below $2 \%[81,85]$.

Conventional $\mathrm{CO}_{2} / \mathrm{CH}_{4}$ separation methods, as well as $\mathrm{CO}_{2} / \mathrm{N}_{2}$ separation, include pressure swing adsorption, cryogenic separation and, as the main technique, chemical absorption by amine, corresponding to $90 \%$ of the installations and being carried out in packed towers, spray towers and bubble columns [81, 86]. Polymeric membranes began to be used for this separation in the 1980s, being the only commercial gas separation application in which membranes are able to compete with traditional separation techniques and still reach only $5 \%$ of a separation equipment market of natural gas that corresponded to 5 billion dollars/year in 2008 [8, 81, $86,87]$.

The membranes used industrially for this separation are polymeric due to the low cost of manufacturing this type of membrane and the ability to adapt to both flat sheet configurations and hollow fiber configurations [81]. The polymers commonly used in $\mathrm{CO}_{2} / \mathrm{CH}_{4}$ separation are polyimide, due to its good chemical, thermal and mechanical stability, spinning capacity and high selectivity, and cellulose acetate, which has been used as a material for making membranes for this separation for 40 years [14, 81]. In these membranes, 
$\mathrm{CO}_{2}$ has greater permeability due to its greater condensability and smaller kinetic diameter $(0.33 \mathrm{~nm}$ compared to $0.38 \mathrm{~nm}$ for $\mathrm{CH}_{4}$ ) [81].

Despite being a promising technology for gas separation, most of these membranes have low resistance to industrial conditions, presenting problems and being difficult to maintain their performance in the long term [81]. In addition, polymeric membranes undergo carbon dioxide-induced plasticization [81]. Plasticization designates the increase in the space between the polymer chains caused by dissolved $\mathrm{CO}_{2}$, with the main effect of increasing gas permeability, which can reach $40 \%$ for cellulose acetate, and the deterioration of membrane selectivity $[8,81]$.

\subsubsection{Production of Oxygen-Enriched Air}

There are polymeric membranes capable of producing nitrogen with purity greater than $95 \%$ from air, however, the oxygen obtained has only moderate purity ( $25-50 \%$ oxygen), also called oxygen-enriched air $[88,89]$. This separation difficulty is due to the close kinetic diameters of the oxygen (3.46 $\AA$ ) and nitrogen $(3.64 \AA)$ molecules [88, 90]. Another problem with membranes normally used in air separation is degradation due to exposure to heavy organic compounds or liquid water even at very low concentrations [88, 91]. For applications that require high purity oxygen (>90\% oxygen), as well as in the presence of liquid water or heavy organics, conventional separation techniques such as solvent absorption, solid adsorption and mainly cryogenic distillation are more indicated $[8,88]$.

Both products of this separation have great application and industrial importance. Oxygen-enriched air finds application in fields such as oxy-combustion, gasification, desulfurization and hydrogen production [88]. The nitrogen obtained can be applied in processes such as cooling, freezing, inerting aircraft fuel tanks and manufacturing adhesives [88].

According to a 2018 literature review study, in the period between the years 2000 and 2017, the five most used polymers in membrane research for oxygen/nitrogen separation were: polysulfone $(23 \%)$, polyimide $(20 \%), \quad$ polyurethane $(7 \%)$, polydimethylsiloxane $(5 \%)$ and polyaniline $(4 \%)$ [88]. Polysulfone is the most promising polymer due to its permeability, selectivity and mechanical resistance, followed by polyimide which also has good mechanical properties, as well as high thermal and chemical stability [88].

Thinking specifically about aspects related to global warming, the use of oxygen-enriched air is very important, especially in processes that involve combustion, because it reduces energy expenditure (by reducing energy losses associated with nitrogen heating) in addition to facilitating the capture of $\mathrm{CO}_{2}$ (for significantly increasing its concentration in the combustion product) [88]. Thus, the use of $\mathrm{N}_{2} / \mathrm{O}_{2}$ and $\mathrm{CO}_{2} / \mathrm{N}_{2}$ separation membranes can make combustion plants, for the most diverse purposes, considerably more environmentally friendly [79].

\subsubsection{Hydrogen Production}

The use of hydrogen as a fuel instead of fossil fuels can help solve problems related to energy security, climate change and air pollution [92]. This is because hydrogen is abundant in the universe, has the highest mass energy content of all fuels and its combustion produces only water as a product [92].

Hydrogen production, mainly by thermochemical methods, generates many by-products such as nitrogen, carbon monoxide or hydrocarbons [92]. The presence of these by-products makes the separation of hydrogen from other gases an important step in the production process [92]. Usually, this purification is carried out commercially by pressure swing adsorption, and can also be performed by cryogenic distillation [92]. However, both methods are energy intensive [92].

Purification processes using membrane separation are low cost, allow to operate with high pressure drops and may reduce the energy consumption of hydrogen production in the future depending on its scale and the purity of the gas produced, provided that some problems are overcome [92]. Among these problems can be mentioned the low operating temperatures required, less than $373 \mathrm{~K}$, the low mechanical and chemical resistance of polymeric membranes, being damaged by compounds such as hydrochloric acid and sulfuroxides $\left(\mathrm{SO}_{\mathrm{x}}\right)$, as well as the high tendency to suffer compaction and swelling [92].

Among the polymeric membranes used for hydrogen separation, polystyrene membranes stand out, with a good combination of permeability to hydrogen and high selectivity in mixtures such as $\mathrm{H}_{2} / \mathrm{N}_{2}, \mathrm{H}_{2} / \mathrm{CH}_{4}$ and $\mathrm{H}_{2} / \mathrm{CO}_{2}$, but other polymers such as polysulfone, polymethylmethacrylate and polyvinylidene fluoride can also be applied [92]. 


\subsection{Challenges To Be Faced}

The development of graphene membranes for gas separation was preceded by several computer simulations that presented evidence that these membranes would be capable of separating gas mixtures with permeabilities and selectivities several orders of magnitude greater than commercial polymeric membranes [93, 94]. The next two sections show the results of computer simulations and experimental studies carried out with a focus on the development of graphene membrane technology for gas separation.

\subsubsection{Simulations}

The studies carried out for simulating gas mixtures separations using graphene membranes are shown in Table 2.

Simulation of $\mathrm{H}_{2} / \mathrm{CH}_{4}$ separation by graphene membranes with pores passivated with nitrogen (dimensions: $3.0 \AA \times 3.8 \AA$ ) or hydrogen (dimensions: $2.5 \AA \times 3.8 \AA$ ) has been reported using first principles density functional theory calculations [95]. The results presented indicate selectivity of $10^{8}$ and $10^{23}$ for passivation with nitrogen and hydrogen respectively, as well as permeability of $1 \mathrm{~mol} \mathrm{~m}^{-2} \mathrm{~s}^{-1} \mathrm{~Pa}^{-1}$ for $\mathrm{H}_{2}$ in the membrane with pores passivated with nitrogen [95]. For comparison, the selectivity of the polymeric membranes for this separation varies between 10 and $10^{3}$ and the permeability of $\mathrm{H}_{2}$ in silica-alumina membranes (more permeable than polymeric membranes) is in the order of $10^{-7} \mathrm{~mol} \mathrm{~m}^{-2} \mathrm{~s}^{-1} \mathrm{~Pa}^{-1}$ [95].

In another work reported in the literature, computer simulation using first principle calculations investigated the permeation of $\mathrm{H}_{2}, \mathrm{He}, \mathrm{O}_{2}, \mathrm{CO}_{2}, \mathrm{CO}, \mathrm{N}_{2}$ and $\mathrm{CH}_{4}$ gases through graphene membranes [96]. The graphene studied had pores passivated with hydrogen of $3,6 \AA$ in diameter [96]. The results obtained indicated, for example, selectivity values of $9 \times 10^{2}$ for the $\mathrm{N}_{2} / \mathrm{O}_{2}$ separation, $2 \times 10^{2}$ for the $\mathrm{CO}_{2} / \mathrm{N}_{2}$ separation and $3 \times 10^{13}$ for the $\mathrm{CO}_{2} / \mathrm{CH}_{4}$ separation [96].

In another research, first principles density functional theory calculations and molecular dynamics were performed to evaluate the separation of $\mathrm{H}_{2} / \mathrm{CO}$, $\mathrm{H}_{2} / \mathrm{N}_{2}$ and $\mathrm{H}_{2} / \mathrm{CH}_{4}$ gases, common mixtures in processes of industrial reform of methane and dehydrogenation of alkanes [97]. Using graphene membranes with pores of $3.2775 \AA$ it was shown that they would be able to separate $75 \%$ of the hydrogen from any of the three mixtures operating with a flow of $1300 \mathrm{~mol} \mathrm{~m}^{-2} \mathrm{~s}^{-1}$ [97].

$\mathrm{H}_{2} \mathrm{~S} / \mathrm{CH}_{4}$ separation has also been studied by molecular dynamics using a $4.05 \AA$ pore size graphene membrane. The results indicated a selectivity of 8.01 with an $\mathrm{H}_{2} \mathrm{~S}$ permeation rate of $9.85 \mathrm{~mol} \mathrm{~m}^{-2} \mathrm{~s}^{-1}$ [98].

Also using molecular dynamics, in another study the separation of $\mathrm{H}_{2} / \mathrm{CO}_{2}, \mathrm{CO}_{2} / \mathrm{N}_{2}, \mathrm{CO}_{2} / \mathrm{Ar}$ and $\mathrm{CO}_{2} / \mathrm{CH}_{4}$ mixtures by graphene with pores size $3.0 \times 3.8 \AA$ passivated with nitrogen was simulated [99]. The results indicated the following selectivity for gas mixtures: 1.6 for $\mathrm{H}_{2} / \mathrm{CO}_{2}, 1400$ for $\mathrm{CO}_{2} / \mathrm{Ar}, 230$ for $\mathrm{CO}_{2} / \mathrm{N}_{2}$ and $6.6 \times 10^{7}$ for $\mathrm{CO}_{2} / \mathrm{CH}_{4}[99]$.

In a study that aimed to evaluate the possibility of applying graphene in the processing of natural gas, molecular dynamics was used to evaluate the separation of the mixtures $\mathrm{CO}_{2} / \mathrm{CH}_{4}, \mathrm{H}_{2} \mathrm{~S} / \mathrm{CH}_{4}$ and $\mathrm{N}_{2} / \mathrm{CH}_{4}$ by graphene membranes with pores of 12 missing aromatic rings [100]. The results indicated permeabilities ranging from $10^{5}$ to $10^{6} \mathrm{GPU}$ for $\mathrm{CO}_{2}, \mathrm{~N}_{2}$ and $\mathrm{H}_{2} \mathrm{~S}$ gases and selectivity of $10^{2}$ [100].

\subsubsection{Experimental Results}

Some studies that performed synthesis of graphene membranes and tested their performance for gas separation are shown in Table 3.

Table 2: Simulations of the Application of Graphene Membranes to Gas Separations. Source: Authors

\begin{tabular}{|c|c|c|}
\hline Separation & Simulation Method & Reference \\
\hline \hline $\mathrm{H}_{2} / \mathrm{CH}_{4}$ & First principles density functional theory calculations & [95] \\
\hline $\mathrm{H}_{2}, \mathrm{He}, \mathrm{O}_{2}, \mathrm{CO}_{2}, \mathrm{CO}, \mathrm{N}_{2}$ e CH $\mathrm{CH}_{4}$ combined in pairs & First principles density functional theory calculations & [96] \\
\hline $\mathrm{H}_{2} / \mathrm{CO}, \mathrm{H}_{2} / \mathrm{N}_{2}$ e H$/ \mathrm{CH}_{4}$ & First principles density functional theory calculations and molecular & Molecular dynamics \\
\hline $\mathrm{H}_{2} \mathrm{~S}_{\mathrm{CH}_{4}}$ & Molecular dynamics & [98] \\
\hline $\mathrm{H}_{2} / \mathrm{CO}_{2}, \mathrm{CO}_{2} / \mathrm{N}_{2}, \mathrm{CO}_{2} / \mathrm{Ar} \mathrm{e} \mathrm{CO}_{2} / \mathrm{CH}_{4}$ & Molecular dynamics & {$[99]$} \\
\hline $\mathrm{CO}_{2} / \mathrm{CH}_{4}, \mathrm{H}_{2} \mathrm{~S} / \mathrm{CH}_{4} \mathrm{e} \mathrm{N}_{2} / \mathrm{CH}_{4}$ & {$[100]$} \\
\hline
\end{tabular}


Table 3: Experimental Studies on the Application of Graphene Membranes to Gas Separations. Source: Authors

\begin{tabular}{|c|c|c|c|}
\hline Separation & Graphene Type & Support & Reference \\
\hline $\mathrm{H}_{2} / \mathrm{CO}_{2}$ & Mechanical exfoliation, 2 layers & Silicon dioxide & {$[101]$} \\
\hline $\mathrm{O}_{2} / \mathrm{N}_{2}$ & $\mathrm{CVD}, 5$ layers & Poly(1-methylsilyl-1-propine) & {$[53]$} \\
\hline $\mathrm{He}$ isolated & $\mathrm{CVD}, 5$ layers & Polycarbonate & {$[51]$} \\
\hline $\mathrm{CO}_{2} / \mathrm{N}_{2}$ & $\mathrm{CVD}, 2$ layers & Polydimethylsiloxane & {$[50]$} \\
\hline $\mathrm{H}_{2} / \mathrm{CH}_{4} \mathrm{e} \mathrm{H}_{2} / \mathrm{C}_{3} \mathrm{H}_{8}$ & $\mathrm{CVD}, 1$ layer & Ponoporous carbon film & {$[94]$} \\
\hline $\mathrm{CO}_{2} / \mathrm{N}_{2}$ & $\mathrm{CVD}, 1$ layer & & {$[44]$} \\
\hline
\end{tabular}

The separation of gases through membranes of approximately $20 \mu \mathrm{m}^{2}$ with two layers of graphene on silicon dioxide substrate has been experimentally tested [101]. Graphene was produced by mechanical exfoliation and sub-nanometric pores were created by oxidative corrosion induced by ultraviolet [101]. The membrane obtained showed a flow of $4.5 \times 10^{-23} \mathrm{~mol} \mathrm{~s}^{-1}$ $\mathrm{Pa}^{-1}$ of $\mathrm{H}_{2}$ and $2.7 \times 10^{-23} \mathrm{~mol} \mathrm{~s}^{-1} \mathrm{~Pa}^{-1}$ of $\mathrm{CO}_{2}$ with selectivity of approximately 2 [101].

In another experimental research, now using graphene obtained by chemical vapor deposition (CVD), a membrane with five layers of graphene was obtained on substrate of Poly(1-methylsilyl-1-propine) (PTMSP) [53]. This membrane showed selectivity of 6 and $\mathrm{O}_{2}$ permeability of 29 Barrer, compared to 1.5 and 730 Barrer of the isolated polymeric support, for $\mathrm{O}_{2} / \mathrm{N}_{2}$ mixture [53].

Again, using the CVD technique for graphene growth, a $5 \mathrm{~mm}^{2}$ membrane consisting of five layers of this material supported by polycarbonate was synthesized [51]. Graphene was transferred directly to the polymer and copper etching was carried out using ammonium persulfate [51]. This membrane had a helium flux $99 \%$ lower than the flow through the isolated polycarbonate [51].

In a work in this same topic, membranes with an area of $3 \mathrm{~cm}^{2}$ composed of two layers of CVD graphene supported by polydimethylsiloxane were prepared [50]. The transfer to the polymeric support was carried out indirectly using polymethylmethacrylate as a temporary support and the etching of the copper was carried out with ammonium persulfate [50]. The gas mixture studied was $\mathrm{CO}_{2} / \mathrm{N}_{2}$ and the graphene layers were responsible for a $30 \%$ reduction in the permeability of these gases compared to the permeability through isolated polydimethylsiloxane $\left(2.1 \times 10^{3}\right.$ Barrer of $\left.\mathrm{CO}_{2}\right)$ [50]. However, graphene was not able to significantly change the selectivity of polydimethylsiloxane which increased from 6.5 to 6.6 with the addition of the bilayer [50].

In a second research using the same gas mixture, a commercial solution of polymethylmethacrylate (PMMA) in chlorobenzene (concentration: 6\% w/w, molar mass: $495000 \mathrm{~g} / \mathrm{mol}$ ) was spread by spin coating on a graphene sheet synthesized on a substrate of copper (purity: $99.8 \%$, thickness: $25 \mu \mathrm{m}$, area: $10 \mathrm{~cm}^{2}$ ), forming a thin film [44]. Spin coating consisted of pouring the PMMA solution onto the surface of the graphene/copper, previously fixed by suction to the equipment and rotated at up to $10,000 \mathrm{rpm}$ [44]. After 5 days, the copper was etched by electrolysis (electrolytic solution: sodium hydroxide $0.01 \mathrm{~mol} / \mathrm{L}$, voltage: $13 \mathrm{~V}$, current: $9 \mathrm{~mA}$ ), releasing the $\mathrm{PMMA} / \mathrm{graphene}$ film in a container with water [44]. It is reported that corrosion by electrolysis is faster, allows reuse of the catalyst and generates a transfer of graphene with a more uniform structure, verified by optical microscopy, compared to corrosion by ammonium persulfate (concentration: $0.1 \mathrm{~mol} / \mathrm{L}$, immersion time: 24 hours) [44]. This film was removed from the water with the aid of a porous PMMA substrate to which it adhered [44]. This support had previously been prepared by phase inversion of a PMMA solution in acetone (concentration: $15 \% \mathrm{w} / \mathrm{w}$, molar mass: $996000 \mathrm{~g} / \mathrm{mol}$ ) using water as a nonsolvent and kept between glass plates for 8 days, until complete drying, to prevent the material from curling and becoming fragile [44]. The polymer thus obtained presented a dense layer and two porous regions, one with larger pores and the other with a more closed microstructure [44]. After the adhesion of graphene, the sides attached to the glass plate were cut and discarded [44]. In this work, greater blocking was achieved by adding graphene, reducing $80 \%$ of the permeability compared to the permeability through isolated polymethylmethacrylate $\left(7.42 \times 10^{-2} \mathrm{GPU}\right.$ for $\mathrm{CO}_{2}$ ) [44]. Again, no significant selectivity changes 
were achieved, increasing from 5.60 to 6.16 with the addition of the graphene layer [44].

Based on the works reported so far, the permeability and selectivity values found experimentally are still far from reaching the values predicted computationally or even to financially compensate for the high cost of graphene production with a view to a possible application on an industrial scale. Methods of synthesis of this material with no defects transferring to the support obtaining totally impermeable surfaces and creating nanopores with angstrom precision and high density still need to be developed.

In this last aspect, the main problem found is that the techniques that produce a high density of pores also create a large amount of non-selective pores which causes a trade-off effect between permeability and selectivity similar to that reported for polymeric membranes [94]. However, a promising result was recently published [94]. Using a technique of creating pores with oxygen plasma followed by ozone treatment, pores with a density of $2.1 \times 10^{12} \mathrm{~cm}^{-2}$ were obtained, with only 22 parts per million of these pores being permeable to $\mathrm{CH}_{4}$ [94]. The pores were created on a monolayer graphene membrane on a nanoporous carbon film support and this membrane was used to separate $\mathrm{H}_{2} / \mathrm{CH}_{4}$ and $\mathrm{H}_{2} / \mathrm{C}_{3} \mathrm{H}_{8}$ mixtures [94]. The results obtained were $\mathrm{H}_{2}$ permeabilities between 1340 and 6045 GPU with selectivity from 15.6 to 25.1 for the $\mathrm{H}_{2} / \mathrm{CH}_{4}$ mixture and from 38.0 to 57.8 for the $\mathrm{H}_{2} / \mathrm{C}_{3} \mathrm{H}_{8}$ mixture [94]. A membrane with these properties of separation of hydrogen and light hydrocarbons would be applicable in the chemical and petrochemical industries, both to produce olefins by the alkane dehydrogenation reaction and for the recovery of hydrogen from the exhaust gas flows of the refinery [94]. These reported results significantly exceeded the 2008 Robson upper limit for polymeric membranes and the $\mathrm{H}_{2}$ permeability is higher than that of the most advanced membranes ever synthesized based on zeolites, graphene oxide, molecular carbon sieves and metal-organic structures [94]. Installed in refineries, these membranes would also be able to recover $90 \%$ of hydrogen from the exhaust gas streams (concentration of up to $35 \%$ hydrogen) with $90 \%$ purity, substantially reducing the capital costs of the operation [94].

It is evident from the difference in kinetic diameters that the $\mathrm{H}_{2} / \mathrm{CO}_{2}$ separation and mainly the $\mathrm{H}_{2} / \mathrm{CH}_{4}$ separation are easier to achieve than some of the other gas separations directly related to the global warming control previously mentioned. However, promising results like these attests to the possibility of synthesis of graphene membranes with transport properties superior to commercial membranes. In addition, the results of the computer simulations encourage further studies with graphene membranes, with their predictions of transport properties unattainable for traditional polymers due to the trade-off, such as high flows and selectivity of the order of $3 \times 10^{13}$ for the $\mathrm{CO}_{2} / \mathrm{CH}_{4}$ separation [96].

Membranes with properties like these for $\mathrm{CO}_{2} / \mathrm{CH}_{4}$, $\mathrm{CO}_{2} / \mathrm{N}_{2}$ and $\mathrm{O}_{2} / \mathrm{N}_{2}$ separations could transform the gas separation market and help slow the greenhouse effect and other environmental problems. These membranes would replace separation processes by amine absorption, reducing the size of plants, energy costs and, mainly, the volume of solvents spent on separation. This takes on an even greater dimension if it is considered that the reduction in the use of solvents has such an environmental importance that it is a principle of Green Chemistry [102].

In the future, separation processes with graphene membranes may further increase efficiency and reduce $\mathrm{CO}_{2}$ capture costs, expanding the application of this technique from a dimension of a few test units in power plants to real applications in practically all large industrial enterprises that perform combustion. This would occur thanks to the already mentioned excellent transport properties of these membranes and chemical and thermal resistance, which would dispense with pretreatments to remove impurities $\left(\mathrm{SO}_{2}, \mathrm{NO}_{x}, \mathrm{HCl}\right.$, particulate materials) and the cooling of the flue gases before separation. In addition, graphene does not suffer from carbon dioxide-induced plasticization, which can reduce failures and increase the life of the membranes.

Graphene membranes may also increase the number of sources of processable methane through membrane separation, since natural gas from reservoirs such as those in the Middle East with concentrations of $\mathrm{H}_{2} \mathrm{~S}$ that reach $30 \% \mathrm{~mol} / \mathrm{mol}$ can be treated by these membranes, as evidenced by computer simulations [14, 98, 103]. This characteristic of the graphene membrane of efficiently separating both $\mathrm{CO}_{2}$ and $\mathrm{H}_{2} \mathrm{~S}$ from natural gas, added to its high resistance to degradation by these substances will allow a great advance compared to polymer membranes. 
Graphene technology, if it reaches its full potential, will also make it possible to obtain high purity oxygen through a process of separation of air by membranes, dispensing pre-treatments to remove liquid water and heavy organic compounds. This will increase the efficiency of oxy-combustion, gasification, desulfurization, hydrogen production, cooling, freezing, inerting aircraft fuel tanks and manufacturing adhesives. Furthermore, these membranes could significantly change the way in which fossil fuel combustion processes are carried out and the environmental consequences of these processes. With the cheaper and more efficient $\mathrm{O}_{2} / \mathrm{N}_{2}$ separation, less and less nitrogen will be inserted unnecessarily into combustion systems, reducing the energy waste for heating this gas and the energy needed to separate the combustion products. With the cheaper and more efficient $\mathrm{CO}_{2} / \mathrm{CH}_{4}$ separation, more and more enterprises will choose to use methane as an energy source, that is, a cleaner, safer and more efficient fuel than other fossil fuels. With the cheaper and more efficient separations required to purify hydrogen, more and more enterprises will choose to use this fuel, which is even better for the environment than natural gas, as it only generates water as a combustion product. Finally, with cheaper and more efficient $\mathrm{CO}_{2} / \mathrm{N}_{2}$ separation, more and more carbon dioxide can be captured after combustion and stored underground instead of being released into the atmosphere.

\section{PERSPECTIVES}

While it is clear that graphene membranes have great potential to contribute both to mitigating the effects of freshwater scarcity events and to slowing global warming, some questions about this technology and the market still need to be answered before it achieves concrete applications.

It is important to say that it is not enough that laboratory tests indicate that the graphene membrane is better than the membranes currently commercialized for it to be successful in the market. In relevant applications involving membrane gas separations, for example, few families of polymers are used for making membranes and they are almost the same as ten years ago. In some separations $\left(\mathrm{O}_{2} / \mathrm{N}_{2}\right.$, for example) this is because there is no commercial appeal for the development of new materials [14]. In others, although there are reports of more selective and permeable materials than these applied industrially, those do not have synthesis procedures as well established as these $[8,14]$. In addition, the tests that determined its properties were carried out under conditions that are far from the actual application, such as low pressures, ambient temperature, pure gases, small areas, short test duration, etc [14].

A clear example of this is the $\mathrm{CO}_{2} / \mathrm{CH}_{4}$ separation that has used cellulose acetate membrane and its derivatives for more than 30 years, since the first generation of commercial membranes to produce natural gas, although this polymer is positioned well below the upper limit of Robeson and undergo plasticization by $\mathrm{CO}_{2}[8,22,23]$. This is due to the fact that this membrane is cheap because cellulose is an abundant and renewable raw material and because the technology for producing cellulose acetate membrane modules is already well developed [8]. Even for membranes with already established synthesis methods on the market, ideal properties are poor indicators of the actual performance of a separation [14]. Cellulose acetate membranes, for example, can suffer a four-fold reduction in their selectivity if pure gas data obtained under ideal conditions are compared with real gas data [14]. Despite this, the data reported in the literature regarding graphene membranes are usually obtained from the permeability of a single gas component and factors such as competitive adsorption and diffusion of gas mixtures are ignored [104]. Thus, before it is determined that graphene membranes are in fact good for a given application, it is necessary to carry out tests with these membranes formed in modules and with durations longer than one week, in addition to realistic process conditions, such as high pressures, presence of different contaminants, depending on the application, and temperatures above room temperature, which has not yet happened [14].

Another major challenge that graphene membrane researchers will encounter will be to show that investing in this technology is as important as investing in studies to improve and modify standard polymeric materials that have already demonstrated their stability and processability [14]. Recent examples of research with this objective are the work of Lu et al. (2019), in which the authors improved cellulose triacetate membranes modified for desalination [105] and the work of Barnett et al. (2020), in which the authors successfully proposed a machine learning algorithm to predict the gas separation behavior of polymers in order to optimize the design of polymeric membranes [106]. Graphene membranes will also face competition from other types of innovative membranes such as polymer membranes with intrinsic microporosity, thermally rearranged polymer membranes, zeolite 
membranes, aquaporin membranes, graphene oxide membranes, carbon nanotube membranes, metalorganic membranes, and ionic liquid membranes with support $[8,15]$.

The implementation of large plants for the synthesis of graphene membranes also needs to be preceded by detailed toxicity studies of graphene, gases and solvents used as raw material so that the design and manufacture are carried out with minimal risks to health and environmental safety [32, 107]. It is also important to define other measures that are not related to toxicity but that ensure that graphene is grown in industrially safe conditions, such as the development of synthesis methods that allow the dilution of flammable gases $\left(\mathrm{H}_{2}\right.$ and $\mathrm{CH}_{4}$ ) to concentrations significantly below their lower explosive limit [34]. Due to the small size and inertia of graphene, it is likely that it can be inhaled and transported to the lungs, become trapped in this organ and cause inflammation or tumor growth, as occurs, for example, with asbestos fibers and coal dust [107]. Another possibility is that, inside the organism, graphene undergoes some type of oxidative degradation, generating reactive oxygen species [108]. In addition, this material has a large hydrophobic surface area, which can cause it to interact with the lipids present in cell membranes, tissues, and organs, presenting some degree of physical toxicity [107]. The active surface of graphene can also cause impurities adsorbed by it to be introduced into the body, such as carcinogenic organic compounds used as solvents during the synthesis steps, which demonstrates the importance of using solvents designed to be biocompatible in the synthesis of this nanoparticle [32]. Meanwhile, factors such as cutaneous absorption of graphene have not even been studied [32].

In relation to the environment, although releases of graphene in nature are expected throughout its life cycle, this is an area of recent research, with unexplored areas such as atmospheric release [32]. In addition to graphene, the surfactants and solvents used in their synthesis can act as pollutants [109]. When released into soil or water, graphene acts as a contaminant, persistent and hydrophobic material, and may suffer reductions in hydrophobicity due to its oxidation, which also increases its risk of detonation $[32,109]$. These particles, if ingested, can, for example, interfere with food intake and the movement of crustaceans and accumulate in the food chain when they are consumed by higher organisms [32]. Over time, this type of phenomenon can generate significant disturbances in ecosystems [32]. Because of its inertia, the only known way to reduce the exposure of environments to graphene is to avoid its emission and this subject needs to be studied in more detail before graphene production increases significantly in scale [32].

Current graphene manufacturing processes are still immature and expensive and the actual content of graphene in products sold on the market can reach levels as low as $50 \%$ with a wide variation depending on the graphene source and manufacturing technique [109]. The development of standardized industrial processes to produce graphene will require synthesis methods that allow the production of this substance with quality and reliability similar to those obtained in research laboratories, massive quantity and attractive price for the market $[31,110]$. Even laboratory production still needs to be improved by discovering techniques that allow, for example, the accurate control of the number of layers [31]. It is possible to achieve these characteristics in batch processes, as in the production of light-emitting diodes (LED's), transistors and solar cells [110]. However, the most appropriate is that the production units are planned to operate continuously and that further studies are devoted to researching how this system could work, especially regarding the homogeneity of heat and mass transfers inside the reactors, since the uniformity of properties throughout the film is very important $[109,110]$.

The high cost of graphene is largely due to the high consumption of electrical energy (for heating at temperatures close to $1000{ }^{\circ} \mathrm{C}$ for up to 48 hours) demanded by the CVD process and the metallic substrate that is lost during the main transfer methods $[31,34,109,110]$. Therefore, it is expected that with the development of research on more efficient growth methods and transfer methods that allow the recovery of the metal, this cost will fall significantly $[31,34,109$, 110]. In addition, for some applications, the unique combination of properties of this material can make its cost irrelevant to a certain extent, as it will not face competition from other existing materials $[109,110]$.

Problems with the availability of raw materials and other inputs (dispersions, solutions, etc.), as well as transport and storage can also arise with the industrial production of graphene, on a scale of millions of square meters per year, and it is necessary to think about ways to avoid them [110]. In this respect, a smart strategy is to produce this material in ways that are already familiar to the chemical and polymer industry, 
which increases the likelihood that similar solutions already exist for the challenges that arise [110].

The global market for graphene is expected to exceed US\$ 180 million by 2025, a value corresponding to graphene as a raw material, not products produced from graphene, which would greatly increase this value [111]. However, analyzing the industry's level of maturity, the resources applied, and the progress already achieved and comparing with the time required for other innovative technologies to reach the market, such as immobilized enzymes and lasers, a period of 20 years for graphene and its membranes reach in fact commercial success seems reasonable $[110,111]$.

Future discoveries that can be disruptive and revolutionary for the graphene membrane market and, consequently, for several other markets should be considered as objectives, albeit distant, for future studies in the area. These innovations include creating techniques for growing graphene at low temperatures and on arbitrary surfaces, without using solvents or using environmentally benign and inexpensive solvents such as water $[15,31]$.

\section{CONCLUSION}

Graphene membranes have shown a huge potential for separation processes in a wide range of applications. However, there are still important constraints that make the experimental results far from the computation simulations, together with high costs for their preparation. The top-down approach aiming at the production of pores in a graphene sheet seems to be closer to the application than bottom-up. Although this study demonstrated a lot of technological flaws to be faced, the gap can be filled by means of investment in this sector. To attain such goal, many players in the market should be convinced of the benefits regarding the understanding of scientific and technical demands to decrease the distance between the academy and the industry. The faster we assemble people with different skills and convince them to achieve this goal, the faster we may apply the technology.

\section{REFERENCES}

[1] Omer A, Elagib NA, Zhuguo M, Saleem F, Mohammed A. Water scarcity in the Yellow River Basin under future climate change and human activities. Science of the Total Environment 2020; 749: 1-13. https://doi.org/10.1016/j.scitotenv.2020.141446

[2] IPCC, Global warming of $1,5^{\circ} \mathrm{C}$. An IPCC Special Report on the impacts of global warming of $1.5{ }^{\circ} \mathrm{C}$ above pre-industrial levels and related global greenhouse gas emission pathways, in the context of strengthening the global response to the threat of climate change, sustainable development, and efforts to eradicate poverty. 2018.

[3] Beddington J. Food, energy, water and the climate: a perfect storm of global events. In: Sustainable Development UK Annual Conference, 2009. QEll Conference Center. Government Office for Science, London.

[4] World Water Assessment Programme, The United Nations World Water Development Report 3: Water in a Changing World. Paris: UNESCO, and London: Earthscan. 2009.

[5] Strosser P, Dworak T, Delvaux PAG, Berglund M, Schmidt G, Mysiak J, Kossida M, lacovides I, Ashton V. Final report Gap Analysis of the Water Scarcity and Droughts Policy in the EU European Commission. European Commission. European Comission. 2012.

[6] International Energy Agency, World Energy Outlook. Paris: Organization for Economic Co-operation and Development, and International Energy Agency. 2006.

[7] Paul D, Ohlrogge K. Membrane separation processes for clean production. Environmental Progress 2006; 17(3): 137141.

https://doi.org/10.1002/ep.670170310

[8] Sanders DF, Smith ZP, Guo R, Robeson LM, Mcgrath J. E Paul DR, Freeman BD. Energy-efficient polymeric gas separation membranes for a sustainable future: A review. Polymer 2013; 54(18): 4729-4761. https://doi.org/10.1016/j.polymer.2013.05.075

[9] Lonsdale HK. What is a membrane? Part II. Journal of Membrane Science 1989; 43(1): 1-3. https://doi.org/10.1016/S0376-7388(00)82348-0

[10] Rautenbach R, Mellis R. Hybrid processes involving membranes for the treatment of highly organic/inorganic contamined waste water. Desalination 1995; 101(2): 105113

https://doi.org/10.1016/0011-9164(95)00013-R

[11] Song N, Gao X, MA Z, Wang X, Wei Y, Gao C. A review of graphene-based separation membrane: Materials, characteristics, preparantion and applications. Desalination 2018; 437: 59-72.

https://doi.org/10.1016/j.desal.2018.02.024

[12] Lattermann S, Höpner T. Environmental impact and impact assessment of seawater desalination. Desalination 2008; 220(1-3): 1-15. https://doi.org/10.1016/i.desal.2007.03.009

[13] Loeb S, Sourirajan S. Sea Water Desmineralization by Means of an Osmotic Membrane. Saline Water Conversion II 1963; P. 117-132. https://doi.org/10.1021/ba-1963-0038.ch009

[14] Buonomenna MG. Design Next Generation Membranes or Rethink the "Old" Asymmetric Membranes? Symmetry 2020; 2(2): 270. https://doi.org/10.3390/sym12020270

[15] Park HB, Kamcev J, Robeson LM, Elimelech M, Freeman BD. Maximizing the right stuff: The trade-off between membrane permeability and selectivity. Science 2017; 356(1137): 1-10. https://doi.org/10.1126/science.aab0530

[16] Henis JMS, Tripodi MK. Composite hollow fiber membranes for gas separation: the resistance model approach. Journal of Membrane Science 1981; 8(3): 233-246. https://doi.org/10.1016/S0376-7388(00)82312-1

[17] Henis JMS, Tripodi MK. The Developing Technology of Gas Separating Membranes. Science 1983; 220(4592): 11-17. https://doi.org/10.1126/science.220.4592.11

[18] Kattula M, Ponnuru K, Zhu L, Jia W, Lin H, Furlani EP Designing ultrathin film composite membranes: the impact of a gutter layer. Scientific Reports 2015; 5(15016). https://doi.org/10.1038/srep15016 
[19] Lu X, Chavez LHA, Castrillón SR, Ma J, Elimelech M. Influence of Active Layer and Support Layer Surface Structures on Organic Fouling Propensity of Thin-Film Composite Foward-Osmosis Membranes. Environmental Science \& Technology 2015; 49(3): 1436-1444. https://doi.org/10.1021/es5044062

[20] Freeman BD. Basis of Permeability/Selectivity Tradeoff Relations in Polimeric Gas Separation Membranes. Macromolecules 1999; 32(2): 375-380. https://doi.org/10.1021/ma9814548

[21] Park HB, Jung CH, Lee YM, Hill AJ, Pas SJ, Mudie ST, Wagner EV, Freeman BD, Cookson DJ. Polymers with Cavities Tuned for Fast Selective Transport of Small Molecules and Ions. Science 2007; 318(5848): 254-258. https://doi.org/10.1126/science. 1146744

[22] Robeson LM. Correlation of separation factor versus permeability for polymeric membranes. Journal of Membrane Science 1991; 2: 165-185.

https://doi.org/10.1016/0376-7388(91)80060-J

[23] Robeson LM. The upper bound revisited. Journal of Membrane Science 2008; 320(1-2): 390-400.

https://doi.org/10.1016/j.memsci.2008.04.030

[24] Geise GM, Park HB, Sagle AC, Freeman BD, Mcgrath JE. Water permeability and water/salt selectivity tradeoff in polymers for desalination. Journal of Membrane Science 2011; 369(1-2): 130-138. https://doi.org/10.1016/j.memsci.2010.11.054

[25] Zhang H, Geise GM. Modeling the water permeability and water/salt selectivity tradeoff in polymer membranes. Journal of Membrane Science 2016; 520: 790-800. https://doi.org/10.1016/j.memsci.2016.08.035

[26] Novoselov KS, Geim AK, Morozov SV, Jiang D, Zhang Y, Dubonos SV, Grugorieva IV, Firsov AA. Electric Field Effect in Atomically Thin Carbon Films. Science 2004; 306(5696): 666-669.

https://doi.org/10.1126/science.1102896

[27] Bunch JS, Verbridge SS, Alden J. S, Van Der Zande AM, Parpia JM, Craighead HG, Mceuen PL. Impermeable Atomic Membranes from Graphene Sheets. Nano Letters 2008; 8(8): 2458-2462.

https://doi.org/10.1021/nl801457b

[28] Cohen-Tanugi D, Grossman JF. Water Desalination across Nanoporous Graphene. Nano Letters 2012; 12(7): 36023608.

https://doi.org/10.1021/nl3012853

[29] Kidambi PR, Jang D, Idrobo J, Boutilier MSH, Wang L, Kong J, Karnik R. Nanoporous Atomically Thin Graphene Membranes for Desalting and Dialysis Applications. Advanced Materials 2017; 29(33): 1-8. https://doi.org/10.1002/adma.201700277

[30] O'hern SC, Stewart CA, Boutilier MSH, Idrobo J, Bhaviripudi S, Das SK, Kong J, Laoui T, Atieh M, Karnik R. Selective Molecular Transport through Intrinsic Defects in a Single Layer of CVD Graphene. ACS Nano 2012; 6(11): 1013010138.

https://doi.org/10.1021/nn303869m

[31] Novoselov KS, Fal'ko VI, Colombo L, Gellert PR, Schwab MG, KIM K. A roadmap for graphene. Nature 2012; 490: 192200

https://doi.org/10.1038/nature11458

[32] Park MVZD, Bleeker EAJ, Brand W, Cassee FR, Elk M, Gosens I, Jong WH, Meesters JAJ, Peijnenburgh WJGM, Quik JTK, Vandebriel RJ, Sips AJAM. Considerations for Safe Innovation: The Case of Graphene. ACS Nano 2017; 11(10): 9574-9593.

https://doi.org/10.1021/acsnano.7b04120

[33] Li X, Cai W, An J, Kim S, Nah J, Yang D, Piner R, Velamakanni A, Jung I, Tutuc E, Banerjee SK, Colombo L, Ruoff RS. Large-Area Synthesis of High-Quality and Uniform
Graphene Films on Copper Foils. Science 2009; 324(5932): 1312-1314.

https://doi.org/10.1126/science.1171245

[34] Wu X, Zhong G, D'arsié L, Sugime H, Esconjauregui $S$, Robertson AW, Robertson J. Growth of Continuous Monolayer Graphene with Millimeter-sized Domains Using Industrially Safe Conditions. Scientific Reports 2016; 6(21152): 1-7. https://doi.org/10.1038/srep21152

[35] Lee KP, Arnot TC, Mattia D. A review of reverse osmosis membrane materials for desalination - development to date and future potential. Journal of Membrane Science 2011; 370(1-2): 1-22. https://doi.org/10.1016/j.memsci.2010.12.036

[36] Cohen-Tanugi D, Grossman JC. Mechanical Strength of Nanoporous Graphene as a Desalination Membrane. Nano Letters $2014 ; 14(11)$ : 6171-6178. https://doi.org/10.1021/nl502399y

[37] Jun S, Tashi T, Park H. Size Dependence of the Nonlinear Elastic Softening of Nanoscale Graphene Monolayers under Plane-Strain Bulge Tests: A Molecular Dynamics Study. Journal of Nanomaterials 2010; 2011: 1-6. https://doi.org/10.1155/2011/380286

[38] Kafiah FM, Khan Z, Ibrahim A, Karnik R, Atieh M, Laoui T. Monolayer graphene transfer onto polypropylene and polyvinylidenedifluoride microfiltration membranes for water desalination. Desalination 2016; 388: 29-37. https://doi.org/10.1016/j.desal.2016.02.027

[39] O'hern SC, Jang D, Bose S, Idrobo J, Song Y, Laoui T, Kong J, Karnik R. Nanofiltration across Defect-Sealed Nanoporous Monolayer Graphene. Nano Letters 2015; 15(5): 3254-3260. https://doi.org/10.1021/acs.nanolett.5b00456

[40] Li S, Lee J, Hu Q, Oh T, Yoo J. Scalable graphene composite membranes for enhanced ion selectivity. Journal of Membrane Science 2018; 564: 159-165. https://doi.org/10.1016/j.memsci.2018.07.005

[41] Jang D, Idrobo J, Laoui T, Karnik R. Water and Solute Transport Governed by Tunable Pore Size Distributions in Nanoporous Graphene Membranes. ACS Nano 2017; 11(10): 10042-10052. https://doi.org/10.1021/acsnano.7b04299

[42] Ghosh AK, Hoek EMV. Impacts of support membrane structure and chemistry on polyamide-polysulfone interfacial composite membranes. Journal of Membrane Science 2009; 336(1): 140-148. https://doi.org/10.1016/j.memsci.2009.03.024

[43] Wood JD, Doidge GP, Carrion EA, Koepke JC, Kaitz JA Datye I, Behnam A, Hewaparakrama J, Aruin B, Chen Y, Dong H, Haasch RT, Lyding JL, Pop E. Annealing free, clean graphene transfer using alternative polymer scaffolds. Nanotechnology 2015; 26(5): 1-9. https://doi.org/10.1088/0957-4484/26/5/055302

[44] Vivas VH. Desenvolvimento de uma membrana composta de grafeno sobre substrato polimérico poroso de PMMA para dessalinização e purificação de água. 2020. 142 p. Thesis (Master in Chemical Engineering). Department of Chemical Engineering, Federal University of Minas Gerais, Belo Horizonte, 2020.

[45] Ali U, Karim KJBA, Buang NA. A Review of the Properties and Applications of Poly (Methyl Methacrylate) (PMMA). Polymer Reviews 2015; 55(4): 678-705. https://doi.org/10.1080/15583724.2015.1031377

[46] Chen Z, Lin CB, Liu W. Hydrolysis Induced Formation of Macrovoids in Poly(methyl methacrylate). Journal of Applied Polymer Science 2006; 99(6): 3451-3465. https://doi.org/10.1002/app.22929

[47] Lai J, Lin F, Wu T, Wang D. On the formation of macrovoids in PMMA membranes. Journal of Membrane Science 1999; 
155(1): 31-43.

https://doi.org/10.1016/S0376-7388(98)00292-0

[48] Sugaya H, Sakai Y. Polymethylmethacrylate: From Polymer to Dialyzer. Contributions to Nephrology 1999; 125: 1-8. https://doi.org/10.1159/000059945

[49] Zulfikar MA, Mohammad AW, Kadhum AA, Hilal N. Poly(methyl methacrylate)/SiO2 Hybrid Membranes: Effect of Solvents on Structural and Thermal Properties. Applied Polymer Science 2005; 99(6): 3163-3171. https://doi.org/10.1002/app.22862

[50] Paraense MO, Cunha THR, Ferlauto AS, Figueiredo KCS. Monolayer and bilayer graphene on polydimethylsiloxane as a composite membrane for gas-barrier applications. Journal of Applied Polymer Science 2017; 134: (47). https://doi.org/10.1002/app.45521

[51] Boutilier MSH, Sun C, O'hern SC, Au H, Hadjiconstantinou NG, Karnik R. Implications of Permeation through Intrinsic Defects in Graphene on the Design of Defect-Tolerant Membranes for Gas Separation. ACS Nano 2014; 8(1): 841849

https://doi.org/10.1021/nn405537u

[52] Qin Y, Hu Y, Koehler S, Cai L, Wen J, Tan X, Xu WL, Sheng Q, Hou X, Xue J, Yu M, Weitz D. Ultrafast Nanofiltration through Large-Area Single-Layered Graphene Membranes. Applied Materials \& Interfaces 2017; 9(11): 9239-9244. https://doi.org/10.1021/acsami.7b00504

[53] Kim HW, Yoon HW, Yoon S, Yoo BM, Ahn BK, Cho YH, Shin HJ, Yang H, Paik U, Kwon S, Choi J, Park HB. Selective Gas Transport Through Few-Layered Graphene and Graphene Oxide Membranes. Science 2013; 342(6154): 91-95. https://doi.org/10.1126/science.1236098

[54] Cheng J, Wang D, Lin F, Lai J. Formation and gas flux of asymmetric PMMA membranes. Journal of Membrane Science 1996; 109(1): 93-107. https://doi.org/10.1016/0376-7388(95)00187-5

[55] Tsai H, Kuo C, Su S, Wang D, Lai J. The morphological evolution of solventcontaining PMMA membranes in various solvent removal processes. Journal of Membrane Science 2009; 345(1): 288-297. https://doi.org/10.1016/j.memsci.2009.09.011

[56] Kuo C, Su S, Tsai H, Su Y, Wang D, Lai J. Formation and evolution of a bicontinuous structure of PMMA membrane during wet immersion process. Journal of Membrane Science 2008; 315(1-2): 187-194. https://doi.org/10.1016/j.memsci.2008.02.034

[57] Lin K, Wang D, Lai J. Nonsolvent-Induced Gelation and Its Effect on Membrane Morphology. Macromolecules 2002; 35(1): 6697-6706. https://doi.org/10.1021/ma020073y

[58] Kerr A, Smith MJ, Cowling MJ, Hodgkiess T. The biofouling resistant properties of six transparent polymers with and without pre-treatment by two antimicrobial solutions. Materials \& Design 2001; 22(5,): 383-392. https://doi.org/10.1016/S0261-3069(00)00093-5

[59] Lin F, Wang D, Lai C, Lai J. Effect of surfactants on the structure of PMMA membranes. Journal of Membrane Science 1997; 23(2): 281-291. https://doi.org/10.1016/S0376-7388(96)00243-8

[60] Wang D, Lin F, Wu T, Lai J. Formation mechanism of the macrovoids induced by surfactant additives. Journal of Membrane Science 1998; 142(2): 191-204. https://doi.org/10.1016/S0376-7388(97)00322-0

[61] Spahis N, Dellali $M$, Mahmoudi $H$. Synthesis and Characterization of Polymeric/Activated Carbon Membranes. In: Water, energy and environment international seminar, 2011. Proceedings [...] Procedia Engineering, 2012; 33: 4751

https://doi.org/10.1016/.jproeng.2012.01.1175
[62] Mekonnen MM, Hoekstra AY. Four billion people facing severe water scarcity. Science Advances 2016; 2(2): 1-6. https://doi.org/10.1126/sciadv.1500323

[63] Elimelech M, Phillip WA. The Future of Seawater Desalination: Energy, Technology, and the Environment. Science 2011; 333(6043): 712-717. https://doi.org/10.1126/science.1200488

[64] Shannon MA, Bohn WP, Elimelech M, Georgiadis JG, Mariñas BJ, Mayes AM. Science and technology for water purification in the coming decades. Nature 2008; 452: 301310.

https://doi.org/10.1038/nature06599

[65] Miller S, Shemer H, Semiat R. Energy and environmenta issues in desalination. Desalination 2015; 366: 2-8. https://doi.org/10.1016/j.desal.2014.11.034

[66] Voutchkov, N. Energy use for membrane seawater desalination - current status and trends. Desalination 2018; 431: 2-14 https://doi.org/10.1016/i.desal.2017.10.033

[67] Amy G, Ghaffour N, LI Z, Francis L, Linares RV, Missimer T, Lattemann S. Membrane-based sea water desalination: Present and future prospects. Desalination 2017; 401: 16-21. https://doi.org/10.1016/j.desal.2016.10.002

[68] Kim J, Park K, Yang DR, Hong S. A comprehensive review of energy consumption of seawater reverse osmosis desalination plants. Applied Energy 2019; 254. https://doi.org/10.1016/j.apenergy.2019.113652

[69] Chinard FP, Enns T. Osmotic Pressure. Science 1956 124(3220): 472-474 https://doi.org/10.1126/science.124.3220.472

[70] Chai G, Krantz WB. Formation and characterization of polyamide membranes via interfacial polymerization. Journal of Membrane Science 1994; 93(2): 175-192.

https://doi.org/10.1016/0376-7388(94)80006-5

[71] Larson RE, Cadotte JE, Petersen RJ. The FT-30 seawater reverse osmosis membrane-element test results. Desalination 1981; 38: 473-483. https://doi.org/10.1016/S0011-9164(00)86092-0

[72] Glater J, Hong S, Elimelech M. The search for a clorineresistant reverse osmosis membrane. Desalination 1994; 95(3): 325-345 https://doi.org/10.1016/0011-9164(94)00068-9

[73] Tang CY, Kwon Y, Leckie JO. Effect of membrane chemistry and coating layer on physiochemical properties of thin film composite polyamide RO and NF membranes: I. FTIR and XPS characterization of polyamide and coating layer chemistry. Desalination 2009; 242(1-3): 149-167. https://doi.org/10.1016/j.desal.2008.04.003

[74] Paul DR. Reformulation of the solution-diffusion theory of reverse osmosis. Journal of Membrane Science 2004; 241(2): 371-386 https://doi.org/10.1016/j.memsci.2004.05.026

[75] Belfort, G. Membrane modules: comparison of different configurations using fluid mechanics. Journal of Membrane Science 1988; 35(3): 245-270.

https://doi.org/10.1016/S0376-7388(00)80299-9

[76] Wendt H, Dermeik S, Ziogas A. Chlorine corrosion of graphites and technical carbons - I. Reaction with gaseous chlorine at elevated temperatures. Materials and Corrosion 1990; 41(8): 457-463.

\section{https://doi.org/10.1002/maco.19900410803}

[77] Mondal MK, Balsora HK, Varshney P. Progress and trends in CO2 capture/separation technologies: A review. Energy 2012; 46(1): 431-441. https://doi.org/10.1016/j.energy.2012.08.006

[78] Yang H, Xu Z, Fan M, Gupta R, Slimane R, Bland AE, Wright I. Progress in carbon dioxide separation and capture: $A$ review. Journal of Environmental Sciences 2008; 20(1): 14- 
27.

https://doi.org/10.1016/S1001-0742(08)60002-9

[79] Powell CE, Qiao GG. Polymeric CO2/N2 gas separation membranes for the capture of carbon dioxide from power plant flue gas. Journal of Membrane Science 2006; 279(1-2): $1-49$.

https://doi.org/10.1016/j.memsci.2005.12.062

[80] Haszeldine RS. Carbon Capture and Storage: How Green Can Black Be? Science 2009; 325(5948): 1647-1652. https://doi.org/10.1126/science.1172246

[81] Zhang Y, Sunarso J, Liu S, Wang R. Current status and development of membranes for $\mathrm{CO} 2 / \mathrm{CH} 4$ separation: A review. International Journal of Greenhouse Gas Control 2013; 12: 84-107. https://doi.org/10.1016/j.ijggc.2012.10.009

[82] House KZ, Harvey CF, Aziz MJ, Schrag DP. The energy penalty of post-combustion $\mathrm{CO} 2$ capture \& storage and its implications for retrofitting the U.S. installed base. Energy and Environmental Science 2009; 2: 193-205.

https://doi.org/10.1039/b811608c

[83] US Energy Department. Basic Research Needs for Carbon Capture: Beyond 2020. 2010.

[84] Adewole JK, Ahmad AL, Ismail S, Leo CP. Current challenges in membrane separation of $\mathrm{CO} 2$ from natural gas: A review. International Journal of Greenhouse Gas Control 2013; 17: 46-65.

https://doi.org/10.1016/j.ijggc. 2013.04.012

[85] Othman MR, Tan SC, Bhatia S. Separability of carbon dioxide from methane using MFI zeolite-silica film deposited on gamma-alumina support. Microporous and Mesoporous Materials 2009; 121(1-3): 138-144.

https://doi.org/10.1016/j.micromeso.2009.01.019

[86] Rufford TE, Smart S, Watson GCY, Graham BF, Boxall J, Diniz DA Costa JC, May EF. The removal of CO2 and N2 from natural gas: A review of conventional and emerging processo technologies. Journal of Petroleum Science and Engineering 2012; 94-95: 123-154.

https://doi.org/10.1016/j.petrol.2012.06.016

[87] Baker RW, Lokhandwala K. Natural Gas Processing with Membranes: An Overview. Industrial \& Engineering Chemistry Research 2008; 47(7): 2109-2121. https://doi.org/10.1021/ie071083w

[88] Himma NF, Wardani AK, Prasetya N, Aryanti PTP, Wenten IG. Recent progress and challenges in membrane-based O2/N2 separation. Reviews in Chemical Engineering 2018; 35(5): 1-35 https://doi.org/10.1515/revce-2017-0094

[89] Smith AR, Klosek J. A review of air separation technologies and their integration with energy conversion processes. Fuel Processing Technology 2001; 70(2): 155-134.

https://doi.org/10.1016/S0378-3820(01)00131-X

[90] Ghosal K, Freeman BD. Gas separation using polymer membranes: an overview. Polymers for Advanced Technologies 1994; 5(11): 673-697. https://doi.org/10.1002/pat.1994.220051102

[91] Prasad R, Notaro F, Thompson DR. Evolution of membranes in commercial air separation. Journal of Membrane Science 1994; 94(1): 225-248. https://doi.org/10.1016/0376-7388(93)E0193-N

[92] Adhikari S, Fernando S. Hydrogen Membrane Separation Techniques. Industrial \& Engineering Chemistry Research 2006; 45(3): 875-881. https://doi.org/10.1021/ie050644|

[93] Paraense MO. Permeação de gases através de membrana composta por grafeno e poli(dimetilsiloxano). 2017. 169 p. Thesis (Master in Chemical Engineering). Department of Chemical Engineering, Federal University of Minas Gerais, Belo Horizonte 2017.
[94]

Zhao J, He G, Huang S, Villalobos LF, Dackchoune M, Bassas $\mathrm{H}$, Agrawal KV. Etching gas-sieving nanopores in single layer graphene with an angstrom precision for highperformance gas mixture separation. Science Advances 2019; 5(1): 1-9. https://doi.org/10.1126/sciadv.aav1851

[95] Jiang D, Cooper VR, Dai S. Porous Graphene as the Ultimate Membrane for Gas Separation. Nano Letters 2009; 9(12): 4019-4024.

https://doi.org/10.1021/n19021946

[96] Qin X, Meng Q, Feng Y, Gao Y. Graphene with line defect as a membrane for gas separation: Design via a first-principles modeling. Surface Science 2013; 607: 153-158. https://doi.org/10.1016/j.susc.2012.08.024

[97] Tao Y, Xue Q, Liu Z, Shan M, Ling C, Wu T, Li X. Tunable Hydrogen Separation in Porous Graphene Membrane: FirstPrinciple and Molecular Dynamic Simulation. ACS Applied Materials \& Interfaces 2014; 6(11): 8048-8058. https://doi.org/10.1021/am4058887

[98] Lei G, Liu C, Xie H, Song F. Separation of the hydrogen sulfide and methane mixture by the porous graphene membrane: Effect of the charges. Chemical Physics Letters 2014; 599: 127-132. https://doi.org/10.1016/j.cplett.2014.03.040

[99] Liu H, Chen Z, Dai S, Jiang D. Selectivity trend of gas separation through nanoporous graphene. Journal of Solid State Chemistry 2015; 224: 2-6. https://doi.org/10.1016/j.jssc.2014.01.030

[100] Sun C, Wen B, Bai B. Application of nanoporous graphene membranes in natural gas processing: Molecular simulations of $\mathrm{CH} 4 / \mathrm{CO} 2, \mathrm{CH} 4 / \mathrm{H} 2 \mathrm{~S}$ and $\mathrm{CH} 4 / \mathrm{N} 2$ separation. Chemical Engineering Science 2015; 138: 616-621. https://doi.org/10.1016/j.ces.2015.08.049

[101] Koenig S, Wang L, Pellegrino J, Bunch JS. Selective molecular sieving through porous graphene. Nature Nanotechnology 2012; 7: 728-732.

https://doi.org/10.1038/nnano.2012.162

[102] Silva FM, Lacerda PSB, Junior JJ. Desenvolvimento sustentável e Química Verde. Química Nova 2005; 28(1): 103-110. https://doi.org/10.1590/S0100-40422005000100019

[103] Babu VP, Kraftschik B, Koros WL. Crosslinkable TEGMC asymmetric hollow fiber membranes for agressive sour gas separations. Journal of Membrane Science 2018; 558: 94105.

https://doi.org/10.1016/j.memsci.2018.04.028

[104] Nidamanuri N, Li Y, LI Q, Dong M. Graphene and Graphene Oxide-Based Membranes for Gas Separation. Engineered Science 2020; 9: 3-16. https://doi.org/10.30919/es8d128906

[105] Lu X, Feng X, Yang Y, Jiang J, Cheng W, Liu C, Gopinadhan $\mathrm{M}$, Osuji CO, Ma J, Elimelech M. Tuning the permselectivity of polymeric desalination membranes via control of polymer crystallite size. Nature Communications 2009; 10(2347): 1-7. https://doi.org/10.1038/s41467-019-10132-0

[106] Barnett JW, Bilchak CR, Wang Y, Benicewicz BC, Murdock LA, Bereau T, Kumar SK. Designing exceptional gasseparation polymer membranes using machine learning. Science Advances 2020; 6(20): 1-7. https://doi.org/10.1126/sciadv.aaz4301

[107] Bradley D. Is graphene safe? Materials Today 2012; 15(6): 230. https://doi.org/10.1016/S1369-7021(12)70101-3

[108] Bianco A. Graphene: Safe or Toxic? The Two Faces of the Medal. Angewandte Chemie International Edition 2013; 52(19): 4986-4997.

https://doi.org/10.1002/anie.201209099 
[109] Lin L, Peng H, Liu Z. Synthesis challenges for graphene industry. Nature Materials 2019; 18: 520-524. https://doi.org/10.1038/s41563-019-0341-4

[110] Zurutuza A, Marinelli C. Challenges and opportunities in graphene commercialization. Nature Nanotechnology 2014;
9: $730-734$.

https://doi.org/10.1038/nnano.2014.225

[111] Reiss T, Hjelt K, Ferrari AC. Graphene is on track to deliver on its promises. Nature Nanotechnology 2019; 14: 907-910. https://doi.org/10.1038/s41565-019-0557-0

Received on 22-09-2021

Accepted on 10-11-2021

Published on 16-11-2021

DOI: https://doi.org/10.15379/2410-1869.2021.08.02.01

(c) 2021 Barcelos et al.; Licensee Cosmos Scholars Publishing House.

This is an open access article licensed under the terms of the Creative Commons Attribution Non-Commercial License

(http://creativecommons.org/licenses/by-nc/3.0/), which permits unrestricted, non-commercial use, distribution and reproduction in any medium, provided the work is properly cited. 